\title{
Maintenance of Epigenetic Information
}

\author{
Geneviève Almouzni ${ }^{1}$ and Howard Cedar $^{2}$ \\ ${ }^{1}$ Department of Nuclear Dynamics and Genome Plasticity, Institut Curie, Section de recherche, 75231 Paris Cedex 05, \\ France; ${ }^{2}$ Department of Developmental Biology and Cancer Research, Institute for Medical Research Israel-Canada, \\ Hebrew University Medical School, Ein Kerem, Jerusalem, Israel 91120
}

Correspondence: genevieve.almouzni@curie.fr

\section{SUMMARY}

The genome is subject to a diverse array of epigenetic modifications from DNA methylation to histone posttranslational changes. Many of these marks are somatically stable through cell division. This article focuses on our knowledge of the mechanisms governing the inheritance of epigenetic marks, particularly, repressive ones, when the DNA and chromatin template are duplicated in S phase. This involves the action of histone chaperones, nucleosome-remodeling enzymes, histone and DNA methylation binding proteins, and chromatin-modifying enzymes. Last, the timing of DNA replication is discussed, including the question of whether this constitutes an epigenetic mark that facilitates the propagation of epigenetic marks.

\section{Outline}

1 DNA methylation

2 Mixing parental and new histones

3 Replication timing
4 Conclusions

References

Editors: C. David Allis, Marie-Laure Caparros, Thomas Jenuwein, Danny Reinberg, and Monika Lachner Additional Perspectives on Epigenetics available at www.cshperspectives.org

Copyright (C 2016 Cold Spring Harbor Laboratory Press; all rights reserved; doi: 10.1101/cshperspect.a019372

Cite this article as Cold Spring Harb Perspect Biol 2016;8:a019372 


\section{OVERVIEW}

Every living organism has the ability to regulate the use of its genetic information. The most basic and usual mechanism for this process uses local regulatory sequences to bind transcription factors that can affect RNA polymerase initiation or elongation of nearby genes. Proteins or protein complexes can operate to either increase RNA synthesis or cause repression. This mechanism is transient in dividing cells because progression of the DNA replication fork usually disrupts these protein-DNA interactions, which then need to be reestablished in the resulting daughter cells. Because this system is based on the recognition of specific sequence elements in the DNA, however, the exact same expression pattern will be reconstructed following division.

The control of expression states using a sequence recognition-based method is perpetually dependent on the dynamic concentration of binding factors in progeny cells. As a result, it represents a nonautonomous mechanism that may not be completely suited for the long-term maintenance and stability of gene expression patterns. Furthermore, $>50 \%$ of the genome in animals is repressed in any individual cell. These observations strongly suggest that higher organisms utilize a different strategy for gene regulation, using more global mechanisms to provide extended stability of gene expression through cell division and even development. In this article, we discuss three different mechanisms that may contribute to long-term epigenetic programming: DNA methylation, the inheritance of chromatin structure through DNA replication, and DNA replication timing. 


\section{DNA METHYLATION}

DNA methylation represents a major mechanism for stable gene repression. DNA methylation refers to the addition of a methyl group to the $5^{\prime}$ position of cytosine residues within a $\mathrm{CpG}$ dinucleotide sequence context in mammals. In general, methylation has a bimodal pattern of distribution in the genome; most regions are highly methylated $(85 \%-$ $100 \%)$, whereas $\mathrm{CpG}$ islands are unmethylated $(0 \%-5 \%)$ (Straussman et al. 2009; Laurent et al. 2010). Many genes, including those only expressed in specific tissues, are located in the methylated fraction, whereas genes with $\mathrm{CpG}$ island promoters (mostly with housekeeping function) are constitutively unmodified.

A great deal is known about how DNA methylation patterns are maintained in vivo. Originally, it was shown that when in vitro-methylated DNA templates are introduced into somatic cells in culture, they retain the exact methylation pattern of the original substrate regardless of sequence, and even after many cell divisions (Pollack et al. 1980; Wigler et al. 1981). This suggested that there must be a mechanism for actually copying the position of methyl moieties during the process of replication. The basis for this lies in the symmetry of CpG dinucleotides-every CpG on one strand has a $\mathrm{CpG}$ complementary to it on the opposite strand, and methylated sites are almost always modified on both strands of the DNA. During the process of replication, however, synthesis of the new strand generates a hemimethylated site. This is, then, specifically recognized by the enzyme Dnmtl (DNA methyltransferase 1) (Li et al. 1992), which then methylates the new CpG, thereby copying the methyl group from the native strand in a semiconservative manner (see Fig. 2 of Li and Zhang 2014). Because the Dnmtl enzyme has a high preference for hemimethylated sites, $\mathrm{CpG}$ sites that are not methylated on the parent strand do not serve as good substrates, thus, preserving their unmodified state on the newly synthesized DNA (Gruenbaum et al. 1982). It is now known that the specificity for this important reaction is not only dependent on the properties of Dnmtl itself, but is aided by additional proteins associated with the replication fork (elaborated in Cheng 2014). As expected, knockdown of either Dnmtl or other proteins in the complex will lead to overall, nonspecific demethylation in dividing cells (Gruenbaum et al. 1981; Lande-Diner et al. 2007).

If the maintenance of DNA methylation patterns is so stable using the Dnmt1-catalyzed process, the question of how patterns can be modified at all during development or ontogeny are intriguing. We know that, in the early morula, most DNA methylation gets erased, but the bimodal pattern is then generated anew at the time of implantation (Monk et al. 1987). This process occurs through a wave of general- ized de novo methylation with CpG islands being protected by virtue of inherent cis-acting sequences, probably related to transcription (Brandeis et al. 1994; Straussman et al. 2009). Following this key stage in development, cells largely lose their ability to perform global de novo DNA methylation, but the original bimodal pattern is preserved through every cell division by the autonomous Dnmt-1-mediated maintenance mechanism (Siegfried et al. 1999). As a result, global methylation patterns seen in individual tissues throughout the organism actually reflect events that occurred at the time of implantation (Fig. 1) (Straussman et al. 2009; Laurent et al. 2010).

The mechanism of copying DNA methylation and histone posttranslational modification (PTM) patterns following DNA synthesis probably plays an important role in gene regulation. Passage of the DNA polymerase complex during replication disrupts nucleosome placement. The original chromatin structure must then be reconstructed on the newly synthesized daughter DNA molecules (Lucchini and Sogo 1995). Because DNA methylation takes part in creating inaccessible chromatin conformations and setting histone modification patterns (Eden et al. 1998; Jones et al. 1998; Nan et al. 1998; Hashimshony et al. 2003), the existence of an autonomous covalent mechanism for preserving DNA methylation patterns greatly helps in this reassembly process. Taken together, this system serves as a global, long-term repression pathway. In this scheme, most regions of the DNA, which are predominantly methylated at CpGs, are automatically put in a relatively closed conformation, whereas $\mathrm{CpG}$ islands are kept open. Global repression is thus achieved without the need to recognize specific sequence elements at each individual gene. It should be noted that although this overall repression state surely plays a role in reducing transcription, this represents only one link in the multilayer process of gene regulation (Lande-Diner et al. 2007).

One of the most important observations confirming the idea that methylation maintenance is based on strand symmetry came from studies of plant DNA. Although methylation in animal DNA was shown to be restricted to $\mathrm{CpG}$ residues, nearest-neighbor analysis revealed that DNA from plant sources can be methylated at all four C-containing dinucleotides. By analyzing further sequence context, however, it turned out that almost all of these methylated C moieties were actually included in the trinucleotide consensus sequence CpXpG (Gruenbaum et al. 1981). This suggested that, in addition to methylation at symmetrical dinucleotide $\mathrm{CpG}$ residues, plant DNA has the ability to maintain methylation patterns at trinucleotide sequences that have symmetrical $\mathrm{C}$ residues located two nucleotides away on the opposite strand. Further studies have indeed confirmed the existence of maintenance enzymes specific 


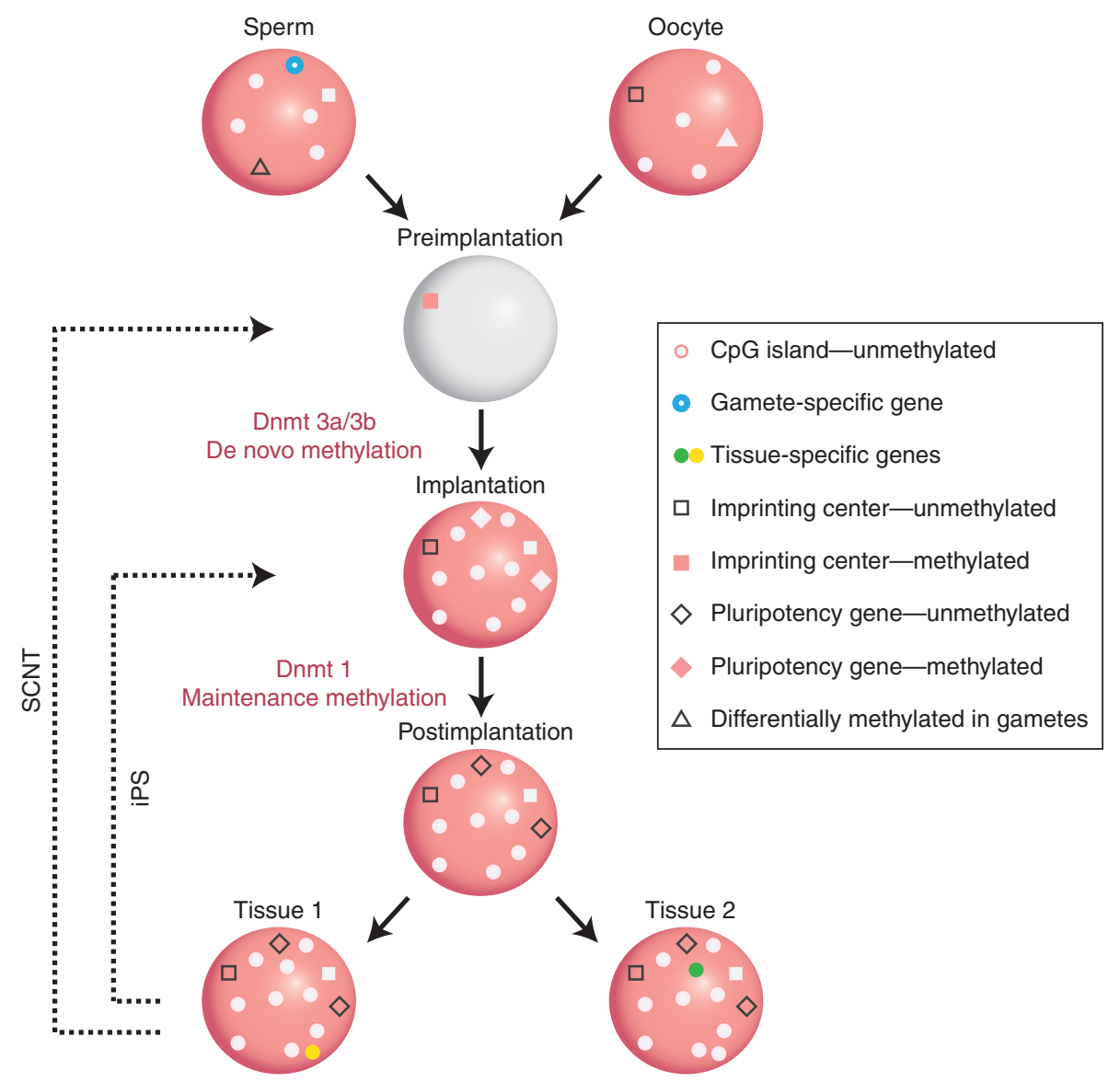

Figure 1. Generation of DNA methylation patterns during development. Gametic cells have a bimodal pattern of methylation with most regions methylated and $\mathrm{CpG}$ islands unmethylated (gray circles). Imprinting centers are methylated in one gamete (pink square), but not the other (white square). Gamete-specific genes (blue ring) are unmethylated. Some genes (triangles) are specifically unmethylated (gray) in one gamete. Almost all methylation in the gametes is erased (gray) in the preimplantation embryo, but imprinting centers retain methylation on one allele (pink square). At the time of implantation, the entire genome gets methylated (pink), with CpG islands being protected (gray circles). Postimplantation, pluripotency genes are de novo methylated (pink diamond). Tissuespecific genes undergo demethylation (yellow in Tissue 1, green in Tissue 2) in their cell type of expression. Imprinting centers remain differentially methylated throughout development. Somatic cell reprogramming by iPS or fusion resets the methylation pattern to the stage of implantation, whereas somatic cell nuclear transplantation (SCNT) resets to the preimplantation state.

for this type of modification site (elaborated in Sec. 2.1 of Pikaard and Mittelsten Scheid 2014).

Proof of a DNA methylation maintenance model in vivo has been obtained from reverse epigenetics experiments in transgenic mice. A loxP-flanked $\mathrm{CpG}$ island element juxtaposed to a non-CpG island sequence upstream of a reporter gene protects the reporter sequence from de novo methylation at the time of implantation and, subsequently, in all tissues of the mouse (Siegfried et al. 1999; Goren et al. 2006). In contrast, if the $\mathrm{CpG}$ island element is removed by early Cre expression, this same reporter will be methylated throughout the animal. Interestingly, when the element is removed by Cre induction in the adult, the re- porter still retains its unmethylated state. This confirms that the pattern of methylation is established in the early embryo and maintained for many cell generations, even if the original cis-acting elements responsible for this pattern are subsequently removed.

Although the basic bimodal DNA methylation pattern of the organism is formed without the need for recognizing specific sequences, all postimplantation changes in methylation take place in a gene- or tissue-specific manner (Fig. 1). By their very nature, these events are primarily driven by interactions between highly specific protein factors and cisacting recognition signals on the DNA. These epigenetic alterations usually accompany changes in gene expression 
and are involved in either demethylation or de novo methylation. Thus, for example, the pluripotency gene, Oct-3/4, undergoes de novo methylation in association with its repression following implantation, whereas many tissue-specific genes undergo demethylation together with their activation during development. In many cases, it is possible that this change in methylation is actually secondary to transcriptional activation or repression (Feldman et al. 2006). Nonetheless, these epigenetic alterations play an important role, at least, by bringing about a new stable state that can be maintained over long periods of time, even in cells that are continuously dividing. The devastating effects of cancer frequently accompanied by the aberrant acquisition or loss of DNA methylation of key genes illustrate the importance of this repressive maintenance mechanism in controlling appropriate gene expression programs (Baylin and Jones 2014). In general, once a programmed change in methylation occurs, it is unlikely to return to its previous state because somatic cells mostly lack the ability to reprogram DNA methylation.

The most striking example of how DNA methylation acts as a cis-acting autonomous marker for gene repression can be seen at imprinted gene regions. In each of these domains, there is always a central imprinting center that dictates differential expression patterns in an allele-specific manner (Barlow and Bartolomei 2014). These centers acquire DNA methylation on one allele during gametogenesis, whereas the other adopts an unmethylated profile. This differential state is then maintained through early embryogenesis (illustrated in Fig. 7 of Barlow and Bartolomei 2014) and into the developing organism, and it is this pattern that ultimately dictates imprinted expression. Indeed, if DNA methylation is erased in the early embryo, imprinting is lost (Li et al. 1993). Similarly, genetic defects that affect methylation of imprinting centers also disrupt allele-specific expression profiles. Allelic methylation is also found on the X chromosomes in female cells (Brockdorff and Turner 2014), in which it is known to play a role in the maintenance of $\mathrm{X}$ inactivation.

Despite the long-term stability afforded by DNA methylation during normal development, we now know that changes that occur as part of the differentiation process can actually be reversed by exposing somatic cells to an embryonic environment. This occurs, for example, when differentiated cell types are fused to embryonic stem (ES) cells in culture or altered by the introduction of pluripotency factors (Hochedlinger and Jaenisch 2014). In this latter case, it appears that these exogenous genes serve to activate endogenous stem-cell master genes, which then turn on the specialized methylation machinery required for setting up a new basal methylation pattern. This occurs, for the most part, in the same manner as in vivo at the time of implantation.

\section{MIXING PARENTAL AND NEW HISTONES}

The organization of DNA into chromatin not only ensures its compaction, but also serves as a versatile structure that offers a range of possibilities for regulating genome function. The chromatin dynamics during DNA replication in eukaryotic cells enables the replication machinery access to compact structures while ensuring maintenance of its chromatin organization. Thus, because of the genomewide alterations in chromatin structure that occur during replication, $S$ phase has been considered a unique window of opportunity for cells to potentially modify chromatin structures that influence gene expression patterns and, thus, cell fate. Chromatin dynamics during replication, therefore, has to meet the dual challenge of maintaining the epigenetic fabric of the genome in a given lineage, but also orchestrating changes in chromatin structure that could promote a switch during cell differentiation and development (see $\mathrm{G}_{2}$ panel of Fig. 2A).

During DNA replication, at the nucleosomal level, two fundamentally distinct processes proceed in parallel: (1) the transient disruption of histone-DNA interaction at preexisting nucleosomes located ahead of replication forks coupled to histone transfer/recycling onto nascent DNA, a reaction known as parental histone segregation; and (2) the deposition of newly synthesized histones through a pathway known as replication-dependent de novo nucleosome deposition (Groth et al. 2007b). Both the segregation of parental histone and de novo chromatin assembly after the replication fork affects the whole genome during each passage through S phase and, most likely, during active transcription and DNA repair at other stages of the cell cycle. Therefore, these two processes, if uncontrolled, can potentially have a widespread and profound impact on the ability of proliferating cells to propagate or modify epigenetic states that depend on specific chromatin structures.

To date, three main categories of factors have been considered during the duplication of chromatin (Fig. 2B): (1) chromatin remodelers, defined as large multiprotein complexes using ATP hydrolysis to slide nucleosomes or remove histones from DNA (Becker and Workman 2013); (2) histone chaperones, which are escort factors that associate with histones and stimulate a reaction involving histone transfer without necessarily being part of the final product (Gurard-Levin et al. 2014); and (3) chromatin modifiers, which are involved in the establishment or removal of PTM marks on histones or, in the case of DNA, methylation of cytosines (Allis et al. 2014). These players, when acting in the vicinity of the replication fork, couple the duplication of DNA with its repackaging into chromatin. We will discuss how histone chaperones and chromatin modifications can possibly contribute to the maintenance of particular 


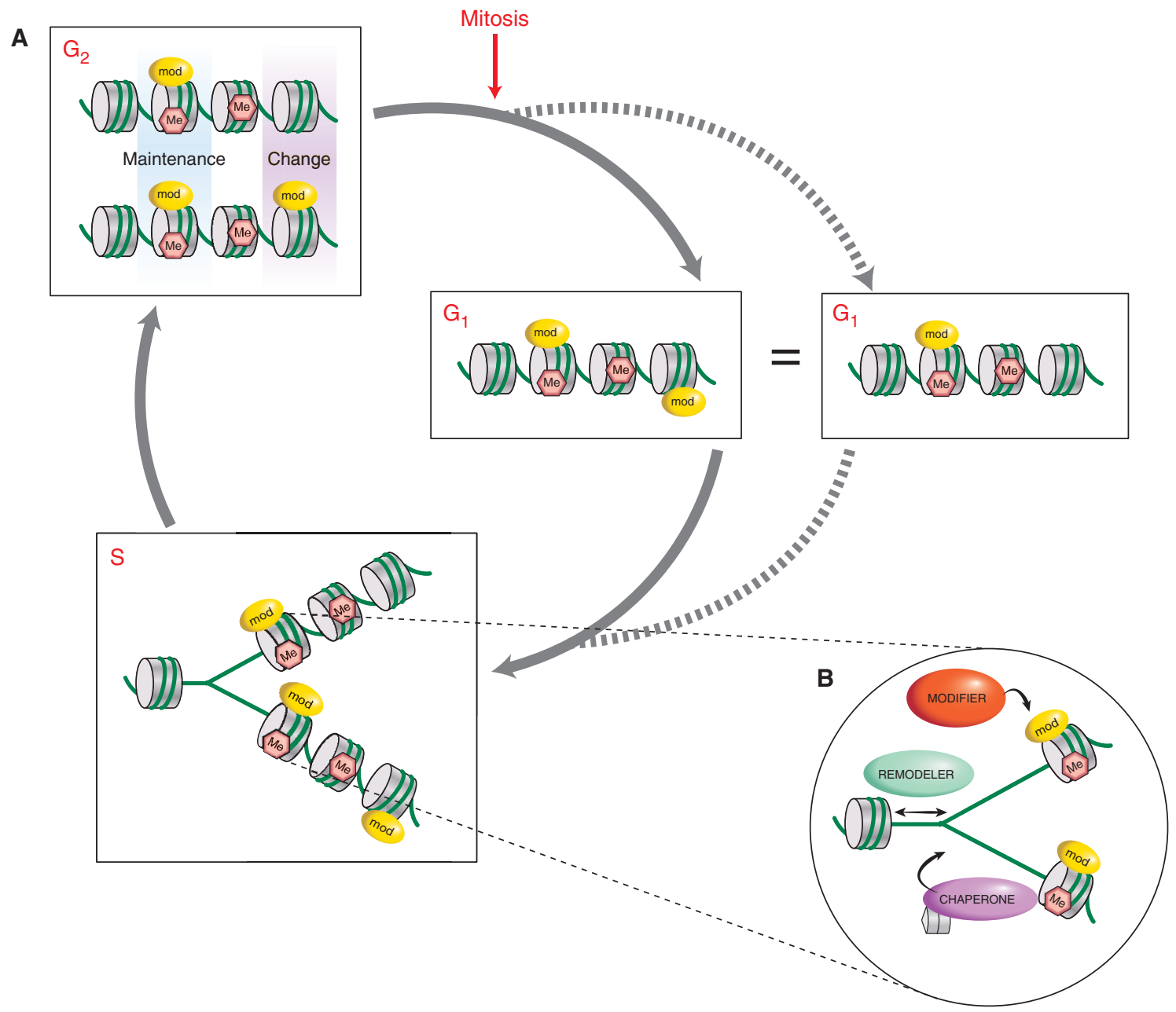

Figure 2. Duplicating chromatin in a cell-cycle-regulated manner. $(A)$ In $\mathrm{G}_{2}$, following DNA replication in $\mathrm{S}$ phase, duplicated chromatin, for the most part, maintains its epigenetic marks (blue shading), and although the opportunity for changes may occur at $\mathrm{S}$ phase, manifests as differences in marks between duplicated chromatin at a locus or region (purple shading). (B) The three types of factors believed to be involved, at the replication fork, in ensuring the propagation of epigenetic marks are chromatin-modifying enzymes (modifiers), nucleosome remodelers, and histone chaperones.

epigenetic marks and, thereby, possibly help to perpetuate cellular memory.

\subsection{Provision of Histones}

\subsubsection{Cell-Cycle-Regulated Synthesis of Histones}

In mammals, if just considering the histone $\mathrm{H} 3$, there are four major variants: the canonical replicative variants $\mathrm{H} 3.1$ and H3.2, replacement variant H3.3, and CENP-A (centromeric protein A), a variant specifically present at centromeres (Loyola and Almouzni 2007; Henikoff and Smith 2014). Replicative histones H3.1 and H3.2 are produced during $S$ phase (Fig. 3) and ensure the provision of new histones to fulfill the requirement for nucleosome assembly on the two daughter strands in the wake of the replication fork (reviewed in Marzluff et al. 2008). Regulatory systems exist to control histone levels through transcriptional and posttranscriptional mechanisms (Gunjan et al. 2005; Marzluff et al. 2008). This is crucial for matching the demand for histones throughout $S$ phase so that all new DNA can efficiently be packaged into nucleosomes while avoiding the deleterious effects of excess histones that can cause impaired replication or chromosome loss (Meeks-Wagner and Hartwell 1986; Gunjan and Verreault 2003; Groth et al. 2007a).

In contrast with the tight cell-cycle regulation observed for canonical histones, replacement (also referred to as replication-independent) histone variants do not show an S-phase regulation during the cell cycle. For example, H3.3 


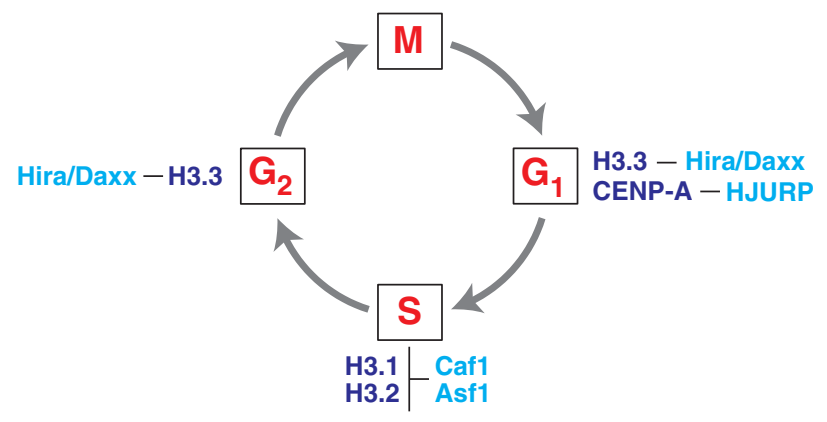

Figure 3. The cell-cycle-regulated provision of histone $\mathrm{H} 3$ variants. Canonical histones H3.1 and H3.2 are expressed mostly during $\mathrm{S}$ phase to ensure the supply of new histone subunits for major de novo chromatin assembly involved during DNA replication. Histone variants show significant incorporation patterns at distinct phases of the cell cycle. Chaperones (cyan) known to function specifically with particular types of histone (dark blue) are indicated.

is predominant in quiescent $\mathrm{G}_{1}$ and $\mathrm{G}_{2}$ phases (Fig. 3) (Wu et al. 1982). CENP-A, the most divergent $\mathrm{H} 3$ variant found at centromeric regions, shows a peak of expression in the $\mathrm{G}_{2}$ phase before nuclear division (Shelby et al. 2000). Thus, when considering histone provision for nucleosome formation, one has to consider both the S-phase-dependent assembly of canonical histones and a replication-independent deposition of replacement histone variants, such as H3.3 and CENP-A (elaborated in Henikoff and Smith 2014).

\subsubsection{Modification of Preassembled Histones}

An important question for understanding chromatin assembly at the replication fork is whether newly synthesized histones have preexisting modifications added before being assembled into chromatin. If so, a follow-up question is: Are these PTMs removed or not on chromatin assembly? Preexisting modifications on histones could influence the final modified state as a given histone-modifying enzyme may or may not work, depending on the histone substrate (Loyola and Almouzni 2007). Another important issue is to understand when and how PTMs are placed or removed, and whether they can account for the selective incorporation of histone variants at specific chromatin locations.

Acetylation is a major modification found on histones before their deposition on chromatin. Histone H4 acetylation, found on the amino-terminal tail at lysine 5 and lysine 12 , is a characteristic mark for newly synthesized histones during S phase in most eukaryotes (Sobel et al. 1995; Loyola et al. 2006). Histones $\mathrm{H} 4$ diacetylated at $\mathrm{K} 5$ and $\mathrm{K} 12$ are found in a complex with the histone chaperones CAF-1 (chromatin assembly factor 1) and Asf1 (antisilencing function 1; discussed further in Sec. 2.2.1), and the K5-, K12-specific histone acetyltransferase, HAT1 (KAT1), be- fore their deposition on chromatin (Fig. 4) (Tagami et al. 2004; Loyola et al. 2006; Parthun 2007). Intriguingly, however, histones $\mathrm{H} 3-\mathrm{H} 4$, which lack their amino-terminal tails, can still be efficiently deposited by CAF-1 onto chromatin in a SV40 DNA replication assay (Shibahara et al. 2000), indicating that histone acetylation-deacetylation is not a limiting step for histone deposition.

Histone $\mathrm{H} 3$ acetylation shows variability between organisms, with a peak in acetylation at K9 and K56 observed during S phase in Saccharomyces cerevisiae, and lower levels in $G_{2} / M$ phases. In mammals, given the limited amount of H3K56ac reported so far in human cells (Garcia et al. 2007; Das et al. 2009; Xie et al. 2009), this mark is unlikely to occur on the bulk of newly synthesized histones, unless it is very rapidly removed after deposition. The role of H3K56 acetylation and chromatin assembly in mammals, thus, awaits further investigation.

Transient acetylation of newly synthesized histones H3 and $\mathrm{H} 4$ can even be observed in heterochromatin, which is largely underacetylated. Histone deacetylation at heterochromatic regions is, in fact, essential for the maintenance of the silent state of heterochromatic regions (Fig. 4) (Agalioti et al. 2002), proper chromosome segregation, and HP1 (heterochromatin protein 1) binding (Ekwall et al. 1997; Taddei et al. 2001). Failure to remove acetyl groups can have deleterious consequences, as shown by the inactivation of HDAC3 (histone deacetylase 3), which leads to impaired Sphase progression (Bhaskara et al. 2008). In addition, improper chromatin maturation on daughter strands could lead to DNA damage.

Loyola et al. (2006) addressed the question of whether or not histone methylation is placed before deposition. Predeposition H3.1 and H3.3 histones show a general lack of methylation marks, with the exception of lysine 9 (Loyola et al. 2006). H3.1 showed mainly H3K9 monomethylation (36\%), whereas H3.3 can be monomethylated $(17 \%)$ or dimethylated (4\%), underscoring that K9 methylation marks may be imposed before deposition on chromatin (Fig. 4). Histone methylation is considered a relatively stable repressive mark at $\mathrm{H} 3 \mathrm{~K} 9$, found mostly at heterochromatin, although several histone lysine demethylases have recently been uncovered (Cloos et al. 2008). Nonnucleosomal H3K9me1 largely depends on the histone methyltransferase SetDB1 (Set domain bifurcated 1, or ESET/KMT1E) in complex with CAF-1 (Fig. 4) (Loyola et al. 2009). Intriguingly, Suv39h, an $\mathrm{H} 3 \mathrm{~K} 9 \mathrm{me} 2 / 3$ histone methyltransferase, operates efficiently on monomethylated, but not dimethylated, H3K9 (Loyola et al. 2006). Thus, a predeposition PTM (i.e., H3K9me1) can potentiate further modification by enzymes (e.g., Suv39h-catalyzed conversion of $\mathrm{H} 3 \mathrm{~K} 9 \mathrm{me} 1$ to me3) to impact on final chromatin states (Fig. 4). The combined action of histone-mod- 


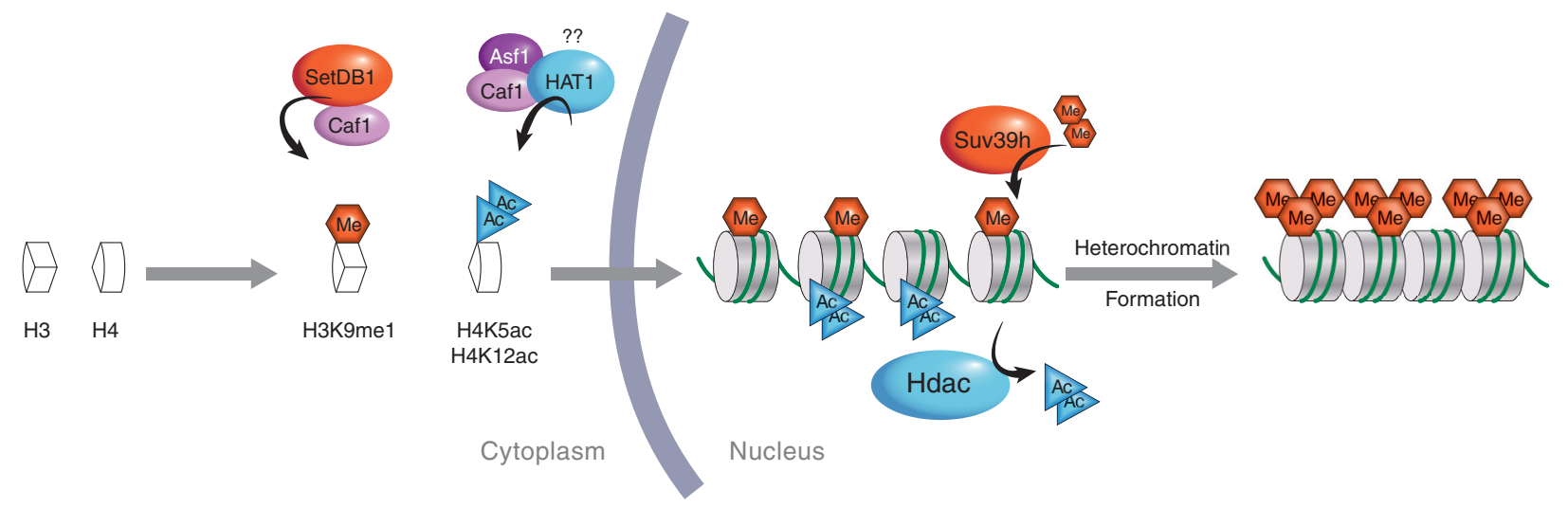

Figure 4. PTM of de novo synthesized histones prechromatin assembly. Histones $\mathrm{H} 3$ and $\mathrm{H} 4$ may have epigenetic marks added before chromatin assembly, which occurs after the replication fork. It is thought that H3K9 monomethylation and H4K5 and H4K12 acetylation are commonly added by modifying enzymes SetDB1 and HAT1, respectively, in complex with histone chaperones (e.g., Caf1 or Asf1). Once chromatin has been assembled, further modification may occur as illustrated in the case of heterochromatin formation.

ifying enzymes before deposition together with the local action of another one during deposition on chromatin will therefore determine the final signature of histones on chromatin. Where and when the modifications occur, and whether, as it has been proposed for the H3K56 and CAF-1 interaction in yeast, certain modifications can facilitate specific interactions with histone chaperones will be important to determine. This may also help to understand whether the modifications can contribute to the specificity of interactions between histone chaperones and particular histone variants discussed in the following section.

\subsection{Histone Dynamics during DNA Replication}

A key question in the research of how epigenetic marks are replicated is how the histone octamer becomes disassembled, transferred, and reassembled on replicated daughter strands of DNA. Also, how is this performed in conjunction with the incorporation of newly synthesized histones? This requires an understanding of the dynamics of chromatin assembly at replication forks, knowledge of the factors involved, and elucidation of how this is coordinated with any propagation or change in histone PTMs. We have, thus far, discussed the cell-cycle-regulated provision of histones and existence of histone PTMs prechromatin assembly. We will now take a closer look at the factors and dynamics involved at the replication fork.

\subsubsection{Histone Chaperones}

We now know that chromatin assembly relies on the activity of histone chaperones, which are histone-binding proteins. Indeed, chaperones are involved in functions as diverse as histone storage, transport, deposition, and eviction. Our understanding of the mechanisms and factors involved in histone deposition began with the development of pioneering cell-free systems consisting of Xenopus laevis egg extracts, which enabled chromatin assembly (Laskey et al. 1977). In 1986, Stillman (1986) biochemically identified human CAF-1, providing the first link between a histone chaperone and the capacity to deposit histones H3-H4 onto replicating DNA (Smith and Stillman 1989). The CAF-1 complex comprises three subunits ( 150 , p60, and RbAp48 in mammals) (Kaufman et al. 1995; Verreault et al. 1996). It is targeted in a phosphorylation-dependent manner to replication forks through an interaction with proliferating cell nuclear antigen (PCNA), a ring-shaped homotrimeric protein that serves as a processivity factor for the DNA polymerases (Fig. 5A) (Shibahara and Stillman 1999; Moggs et al. 2000; Gerard et al. 2006). A function of CAF-1 may be to ensure a tight coordination between histone deposition and ongoing DNA replication. The in vivo importance of CAF-1 is underscored by depletion studies in which loss of CAF-1 results in the loss of viability during development in mouse (Houlard et al. 2006), Xenopus (Quivy et al. 2001), and Drosophila (Song et al. 2007; Klapholz et al. 2009) and impaired S-phase progression in human cells (Hoek and Stillman 2003). More detail of its precise roles is elaborated in the following section.

Asf1 is another H3-H4 histone chaperone, identified initially in yeast, in a screen for silencing defects on overexpression (Le et al. 1997). Like CAF-1, it facilitates chromatin assembly coupled to DNA synthesis in vitro (Fig. 5) (Tyler et al. 1999; Mello et al. 2002). However, the sole addition of Asf1 to human cell extracts, or in HIRA (histone cell cycle regulator homolog A) and Asf1-depleted 


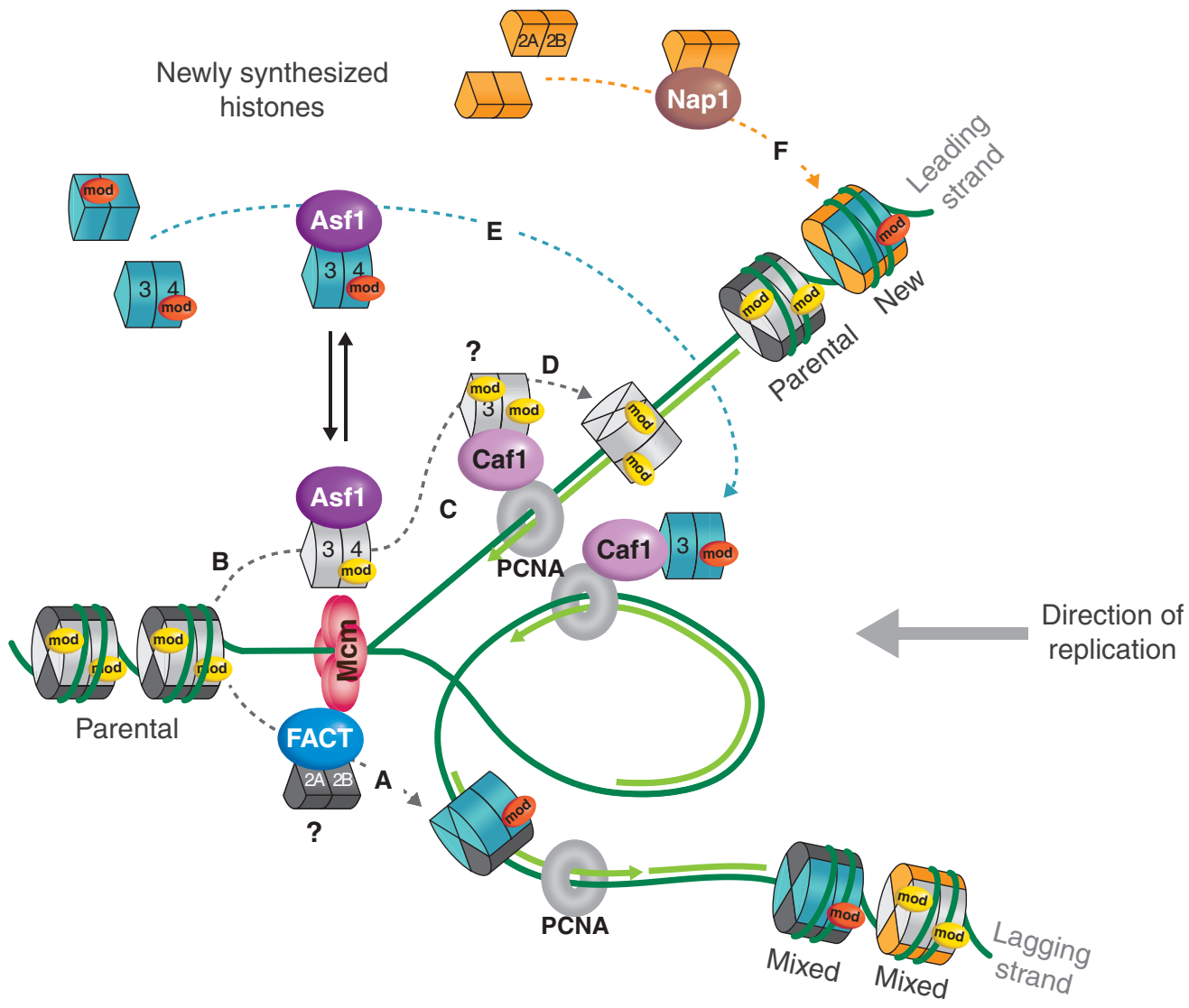

Figure 5. Chaperones and histone dynamics at the replication fork in eukaryotic cells. DNA replication proceeds in an asymmetric manner with continuous synthesis on the leading strand and discontinuous synthesis on the lagging strand. Folding of the two strands in space ensures coupling of replication between the two strands. Two fundamental processes affect the basic unit of chromatin during replication: "nucleosome removal" in front of the replication fork and "nucleosome deposition" on the two daughter strands behind the fork. Disruption of parental nucleosomes into two H2A-H2B dimers and an $(\mathrm{H} 3-\mathrm{H} 4)_{2}$ tetramer (or two H3-H4 dimers?) and their transfer/recycling onto the newly synthesized daughter strands provides a first source of histones (stages $A-D$ ). De novo assembly of new histones (H3-H4 as dimers in complex with histone chaperones) is necessary to restore a full nucleosomal density on the duplicated material (stages $E$ and $F$ ). During $S$ phase, this pool is provided by synthesis of replicative histone $\mathrm{H} 3.1$ variants in mammals. Although new histones carry a typical diacetylation K5, K12 modification on histone $\mathrm{H} 4$ (red "mod"), parental histone PTMs (yellow mod) potentially preserved during transfer can be used as a blueprint to reproduce marks on newly incorporated histones, which could be a means for epigenetic inheritance. How such events function in coordination with progression of the replication fork remains an open issue. The MCM (minichromosome maintenance) 2-7 is thought to mediate DNA unwinding in front of the replication fork. The histone binding activity of $\mathrm{Mcm} 2$ could aid the disruption, possibly in conjunction with chromatin remodelers and/or histone modifiers. An interaction with the MCM2-7 complex could favor targeting of the histone chaperones Asf1 and FACT (facilitates chromatin transcription), which would handle, respectively, parental $\mathrm{H} 3-\mathrm{H} 4(B)$ and $\mathrm{H} 2 \mathrm{~A}-$ $\mathrm{H} 2 \mathrm{~B}(A)$. In addition, Asf1 could pass parental histones onto CAF-1 $(C)$. Because Asf1 interacts with $\mathrm{H} 3-\mathrm{H} 4$ in the form of dimers, parental tetramers (with their own marks) could potentially split and redistribute as dimers in a semiconservative fashion onto daughter strands. The reassembly on nascent DNA, in a stepwise fashion, would proceed via recruitment of CAF-1 to PCNA, which mediates the deposition of H3-H4 dimers provided by Asf1 acting as a histone donor $(E)$. Having Asf1 handling both new and parental histones $(C$ and $E$ ) would provide a means to coordinate histone supply with replication fork progression. With dynamics of $\mathrm{H} 2 \mathrm{~A}-\mathrm{H} 2 \mathrm{~B}$ being relatively important throughout the cell cycle, it may be that assembly of these histones could simply use the NAP1 histone chaperone for $\mathrm{H} 2 \mathrm{~A}-\mathrm{H} 2 \mathrm{~B}$ without a particular need to have a direct connection with the replication fork. NAP1 would bring in new histones $\mathrm{H} 2 \mathrm{~A}-\mathrm{H} 2 \mathrm{~B}$, and possibly old $\mathrm{H} 2 \mathrm{~A}-\mathrm{H} 2 \mathrm{~B}$, made available from transcriptional exchange $(C)$. (Adapted, with permission, from MacAlpine and Almouzni 2013, C Cold Spring Harbor Laboratory Press.) 
$X$. laevis egg extracts, is not sufficient to promote chromatin assembly or histone deposition. This indicates that Asf1 is unlikely to play a direct role in either replication-coupled or replication-independent chromatin assembly pathways (Mello et al. 2002; Ray-Gallet et al. 2007). Rather, it may act as a histone donor for the histone chaperone CAF-1 during DNA replication or repair (Fig. 5A,B), a collaboration conserved in various organisms. This is corroborated by the fact that Asf1 interacts with the B-domain of the p60 subunit of CAF-1 through a conserved hydrophobic groove (Tyler et al. 2001; Mello et al. 2002; Sanematsu et al. 2006; Tang et al. 2006; Malay et al. 2008) at a site opposite to that of its interaction with H3-H4 (English et al. 2006; Natsume et al. 2007). Formation of a ternary complex (CAF-1Asf1-H3-H4) could thus be an intermediate, enabling histones to be handed over from one chaperone to the next. Hence, such histone transfer from Asf1 to CAF-1, as part of an "assembly line," would ensure an efficient histone deposition coupled to DNA replication (Fig. 5A or 5B). Other histone chaperones also have to be considered as players in histone dynamics. For example, NASP (nuclear autoantigenic sperm protein) is a chaperone for linker histone $\mathrm{H} 1$ (Finn et al. 2008), H3-H4 (Osakabe et al. 2010), and as part of a multichaperone complex (Tagami et al. 2004; Groth et al. 2005). There are also H2A-B-specific chaperones, such as Nap1 and FACT, not elaborated here, but illustrated in Figure 5D,E.

Stability of the histone $(\mathrm{H} 3-\mathrm{H} 4)_{2}$ tetramer when it is free of DNA in solution (Baxevanis et al. 1991) led to the long-standing assumption that these histones were deposited directly as a tetramer entity. Recent data have now challenged this view; histones $\mathrm{H} 3-\mathrm{H} 4$ were found as dimers together with histone chaperones within predeposition complexes in human cells (Fig. 5) (Tagami et al. 2004). Moreover, investigation of CenH3 (centromeric-specific H3) nucleosome properties identified hemisomes containing one copy of CenH3, H2A, H2B, and H4 each (Dalal et al. 2007). Together, these data suggest that histones H3$\mathrm{H} 4$ or CenH3-H4 can first be provided as dimers. Two H3$\mathrm{H} 4$ dimers next associate during deposition onto replicating DNA to form tetramers (Fig. 5C). The crystal structure of Asf1 interacting with a dimer of histones $\mathrm{H} 3-\mathrm{H} 4$ revealed that Asf1 physically blocks the formation of a $(\mathrm{H} 3-\mathrm{H} 4)_{2}$ tetramer (English et al. 2006; Natsume et al. 2007). However, whether both new histone $\mathrm{H} 3-\mathrm{H} 4$ dimers are provided by Asf1 and then deposited by CAF-1 onto DNA or additional chaperones are involved remains a possibility.

The NAP- 1 chaperone adds histones H2A-H2B following the delivery of two dimers of H3-H4 onto newly synthesized DNA (Zlatanova et al. 2007), forming a complete nucleosomal core particle (Fig. 5D). Incorporation of new $\mathrm{H} 2 \mathrm{~A}-\mathrm{H} 2 \mathrm{~B}$, however, does not necessarily have to be tightly linked to DNA replication, as significant $\mathrm{H} 2 \mathrm{~A}-\mathrm{H} 2 \mathrm{~B}$ exchange also occurs outside replication (Kimura and Cook 2001). The FACT complex also acts as an H2A-H2B chaperone in transcription and DNA repair, as well as in DNA replication (Fig. 5E). The apparent similarity of substrate and locality of action of the FACT and NAP- 1 chaperones begs the question of what their precise functions are, and whether there is cross talk between them (Krogan et al. 2006).

\subsubsection{Histone Dynamics at the Replication Fork}

The nature of parental histones, in terms of variant composition and the ensemble of PTMs, represents information that can modulate genome function. Elucidating the dynamics of nucleosomes/histones in front of the replication machinery, combined with the handling of parental histones, is essential for understanding the parameters that govern the maintenance or loss of this information during replication.

Early studies by electron microscopy indicated that about 1 to 2 nucleosomes are destabilized in front of the fork in cell culture (Sogo et al. 1986; Gasser et al. 1996). However, determining whether destabilization involves a stepwise disassembly of the histone core octamer or, rather, a coordinated transfer of the octamer on the daughter strands is not yet clear. The fact that replication of SV40 mini-chromosomes with cross-linked nucleosomes can occur in human cell extracts, although at a reduced speed, indicates that dissociation of the histone octamer is not an absolute requirement for the passage of the replication fork and transfer of the parental nucleosomes (Vestner et al. 2000). In vivo metabolic labeling studies, however, led to the view that the core histone octamer is disrupted into two $\mathrm{H} 2 \mathrm{~A}-\mathrm{H} 2 \mathrm{~B}$ dimers and a histone $(\mathrm{H} 3-\mathrm{H} 4)_{2}$ tetramer (Fig. 6A) (Annunziato 2005). More recently, the use of isotope labeling, combined with mass spectrometry analysis of histone content, has shed light on whether the histone (H3$\mathrm{H} 4)_{2}$ tetramer remains intact during transfer (Xu et al. 2010); the vast majority of $\mathrm{H} 3.1-\mathrm{H} 4$ tetramers do not split, but the investigators did observe a significant number of splitting events for the H3.3-containing tetramers (Fig. $6 \mathrm{~B})$. Together with the provision of newly synthesized histones as dimers (Fig. 6C) (Tagami et al. 2004), ultimately, three modes of $\mathrm{H} 3-\mathrm{H} 4$ partitioning during nucleosome assembly at the replication fork can be considered: the transfer of parental histones onto replicated DNA, deposition of mixed old and new, and assembly of only newly synthesized histones (Fig. 6). It will be important to determine whether mixing events are exclusively variant-specific or if they reflect particular histone dynamics associated with specific chromatin regions. 
Parental nucleosome
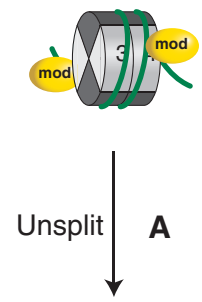

$(\mathrm{H} 3-\mathrm{H} 4)_{2}$ tetramer

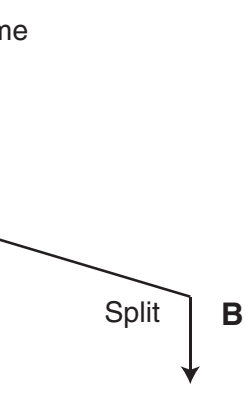

H3-H4 dimers
Newly synthesized histones

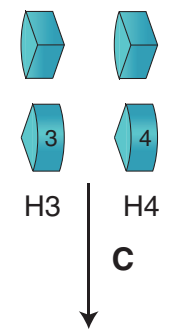

H3-H4 dimers

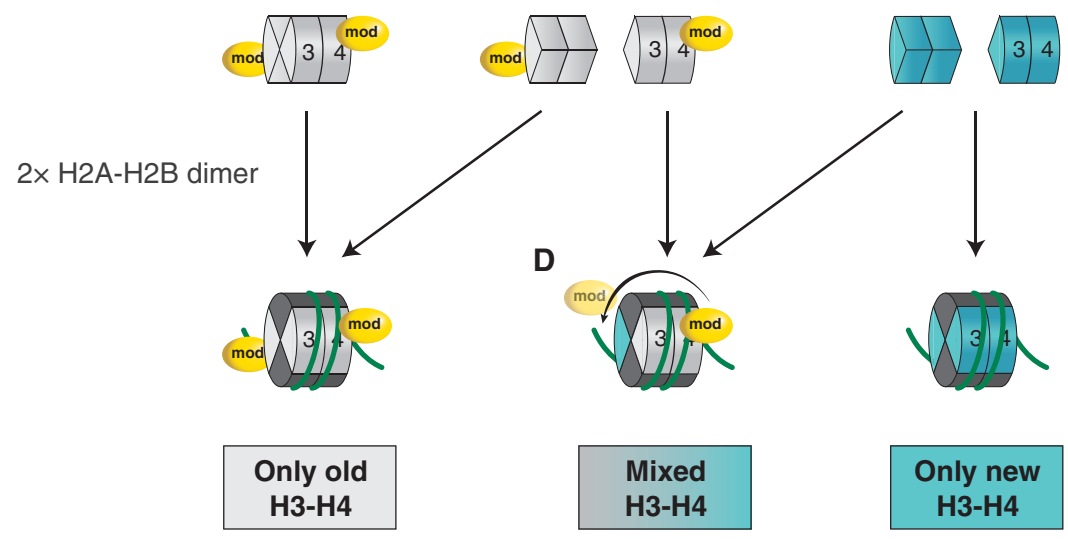

Figure 6. H3-H4 partitioning during nucleosome assembly. Upon nucleosome disruption during replication, parental $(\mathrm{H} 3-\mathrm{H} 4)_{2}$ tetramers can either remain intact (Unsplit) or broken up into two H3-H4 dimers (Split). Old nucleosomes will form either by inheritance of a stable $(\mathrm{H} 3-\mathrm{H} 4)_{2}$ tetramer $(A)$ or by self-reassociation of two old recycled $\mathrm{H} 3-\mathrm{H} 4$ dimers $(B)$. On the other hand, new nucleosomes result from de novo assembly of two newly synthesized H3-H4 dimers $(C)$. Mixed particles can form on daughter strands by mixing an old H3-H4 dimer together with a new H3-H4 dimer $(D)$. In all cases, association of two $\mathrm{H} 2 \mathrm{~A}-\mathrm{H} 2 \mathrm{~B}$ dimers is necessary to complete the nucleosome. A modification on $\mathrm{H} 4$ is illustrated on the parental nucleosome to show the concept of intraparticle propagation of the mark between parental and new histones $(D)$. (Adapted, with permission, from Nakatani et al. 2004; also MacAlpine and Almouzni 2013, (C) Cold Spring Harbor Laboratory Press.)

Disruption of the nucleosome during DNA replication may be achieved by the driving force of the moving fork, for example, through progression of the replicative helicase (Ramsperger and Stahl 1995). Interestingly, the large Tantigen viral helicase and the MCM2-7 helicase bind histone H3 (Ramsperger and Stahl 1995; Ishimi et al. 1998) and, as ATP-driven machines, these helicases can provide the energy for the disruptive process. Interestingly, human cells depleted of Asf1 show defects in DNA unwinding, implicating its loss as impairing the removal of the nucleosome, so creating a barrier for replication fork progression (Groth et al. 2007a). This is corroborated by the fact that histones carrying typical parental PTMs can be detected in association with Asf1 on replication stress, suggesting that Asf1 can function as an acceptor of recycled parental dimers (Fig. $5 \mathrm{~F}$ ), as well as the previously mentioned role in chaperoning de novo synthesized H3-H4 dimers (Sec. 2.2.1) (Groth et al. 2007a; Jasencakova et al. 2010). Collectively, these results suggest that nucleosome disruption is closely coordinated with DNA unwinding in close proximity of the replication fork. However, additional factors acting at the histone level may also facilitate this process (see Sec. 2.2.3). Consequent to disruption, the consensus is that parental histones are randomly segregated on both sides of the replication fork (i.e., parental, mixed, or new), as illustrated in Figure 5 (Annunziato 2005). However, one can imagine that alternative mechanisms may operate at specific loci and in particular cell types, such as stem cells, which may harbor particular properties. Thus, whether the general principle of random segregation applies genome wide and during all stages of development requires further investigation.

In summary, three crucial steps (disruption, transfer, and de novo deposition) must take place for the duplication of chromatin organization during DNA replication. These events should not be considered independently but rather as a coordinated continuum between disruption, transfer, and de novo deposition, surrounding replication fork progression (Fig. 5), which is essential for preserving genetic stability and chromatin organization. 


\subsubsection{Propagating Histone Modifications}

DNA methylation, histone PTMs, and even the incorporation of histone variants into nucleosomes provide extra layers of information that may be termed "epigenetic" if stably inherited throughout cell generations. The question of whether they are perpetuated during DNA and chromatin duplication or their stable propagation through multiple cell divisions occurs independently of DNA replication continues to be assessed. Our current understanding of the models and mechanisms by which these marks are propagated during DNA replication are discussed here. The manner in which DNA methylation is inherited requires that the preexisting methylation pattern on $\mathrm{CpG}$ is copied onto the new DNA strand after DNA replication via Dnmt1 (Sec. 1). One can envision that histone PTMs could also be perpetuated during DNA replication to maintain cell identity.

For the maintenance of histone PTMs, parental histones might be used as a template for the modification of new histones. Current models describing the random distribution of parental and newly synthesized histones on daughter strands suggest that neighboring parental histones serve as a template to spread a given modification to a de novo assembled nucleosome (for reviews, see Nakatani et al. 2004; Probst et al. 2009). Accordingly, the parental nucleosome would remain intact and no splitting of $\mathrm{H} 3-\mathrm{H} 4$ tetramers would be required (Fig. 6A) (Annunziato 2005). Such a mechanism can be effective in repetitive regions in which long arrays of nucleosomes carry the same marks, such as in pericentric heterochromatin in which $\mathrm{H} 3 \mathrm{~K} 9 \mathrm{me} 3$ is bound by HP1 proteins (Bannister et al. 2001; Lachner et al. 2001). However, it cannot apply to regions in which particular marks are restricted to only one or two nucleosomes. In these regions, the splitting of tetramers, as recently observed with H3.3 variants (e.g., Fig. 6B) (Xu et al. 2010), could lead to the transmission of histone marks through an intraparticle mechanism (Fig. 6D).

To take the example of pericentric heterochromatin, in which the replication of not only DNA, but epigenetic information, such as histone marks and spatial organization, needs to occur, propagation represents a challenge. The maintenance of DNA and histone methylation patterns following DNA replication is, in fact, crucial for the stability of the genome and cell division. The local concentration of HP1 proteins, together with DNA methylation and $\mathrm{H} 3 \mathrm{~K} 9 \mathrm{me}$, all contribute to the formation of these constitutive heterochromatic regions next to centromeres via a spreading mechanism that may partly rely on the templating of marked parental nucleosomes distributed randomly after DNA replication (Fig. 7A).

A common theme in the transmission of DNA methylation patterns or histone PTMs is the coupling of the enzymatic activity with the replication process. This may be facilitated via the interaction of several factors implicated in the duplication of epigenetic marks with PCNA, which is a major component of the replication fork machinery. Known interacting proteins include Dnmt1 (Fig. 7B), which is the principal enzyme responsible for propagating cytosine methylation inheritance owing to its preferred affinity for hemimethylated CpG motifs (Pradhan et al. 1999), CAF-1, introduced as a histone chaperone in the previous section, and Pr-Set7, discussed below.

Mouse CAF-1 p150 is required for replication of pericentromeric heterochromatic regions (Quivy et al. 2008). The largest subunit of CAF-1, p150, binds HP1 (Murzina et al. 1999) and this interaction is essential to promote the redistribution of HP1 during replication (Fig. 7C) (Quivy et al. 2004). An attractive hypothesis is that, by handling HP1 proteins, mouse CAF-1 p150 would relieve physical constraints impeding replication fork progression in HP1rich pericentromeric heterochromatic regions and ensure an effective redeposition of HP1 molecules behind the fork on recycled $\mathrm{H} 3 \mathrm{~K} 9 \mathrm{me} 3$-marked parental histones (Quivyet al.2008; Loyola et al. 2009). A self-reinforcing loop involving the histone H3K9 methyltransferase Suv39h recruited by HP1 (Aagaard et al. 1999) would then create additional binding sites for HP1 (Fig. 7A). This would explain the propagation of HP1 binding in pericentric heterochromatin. The identification of a multimeric complex composed of the H3K9 histone methyltransferases Suv39h1, G9a, GLP, and SetDB1 is consistent with this view, implicating all of the KMTs (lysine methyltransferases) in the process of heterochromatin formation (Fig. 7) (Fritsch et al. 2010).

CAF-1 is also found in a complex together with MBD1 (methyl-CpG-binding protein 1), a protein that binds to methylated CpG motifs, and the histone $\mathrm{H} 3 \mathrm{~K} 9$ methylase SetDB1 (Reese et al. 2003; Sarraf and Stancheva 2004). A current hypothesis is that passage of the replication fork may displace MBD1, facilitating its interaction with the CAF-1 p150 subunit (Reese et al. 2003) to form a SetDB1-MBD1-CAF1 S-phase-specific complex (Fig. 7D) (Sarraf and Stancheva 2004). This epigenetic memory would ensure the coupling of postreplicative transmission of DNA and H3K9 methylation with nucleosomal assembly. In addition, MBD1 can interact with the histone methyltransferase Suv39h1 and HP1 (Fujita et al. 2003), which could provide another means to perpetuate $\mathrm{H} 3 \mathrm{~K} 9$ methylation states and chromatin compaction (Fig. 7A).

In mammals, the HDAC responsible for $\mathrm{H} 4 \mathrm{~K} 5, \mathrm{~K} 12$ deacetylation remains unknown, yet deacetylation is observed within 20-60 min of chromatin assembly (Taddei et al. 1999). In Drosophila, deacetylation of H4K5,K12 depends 


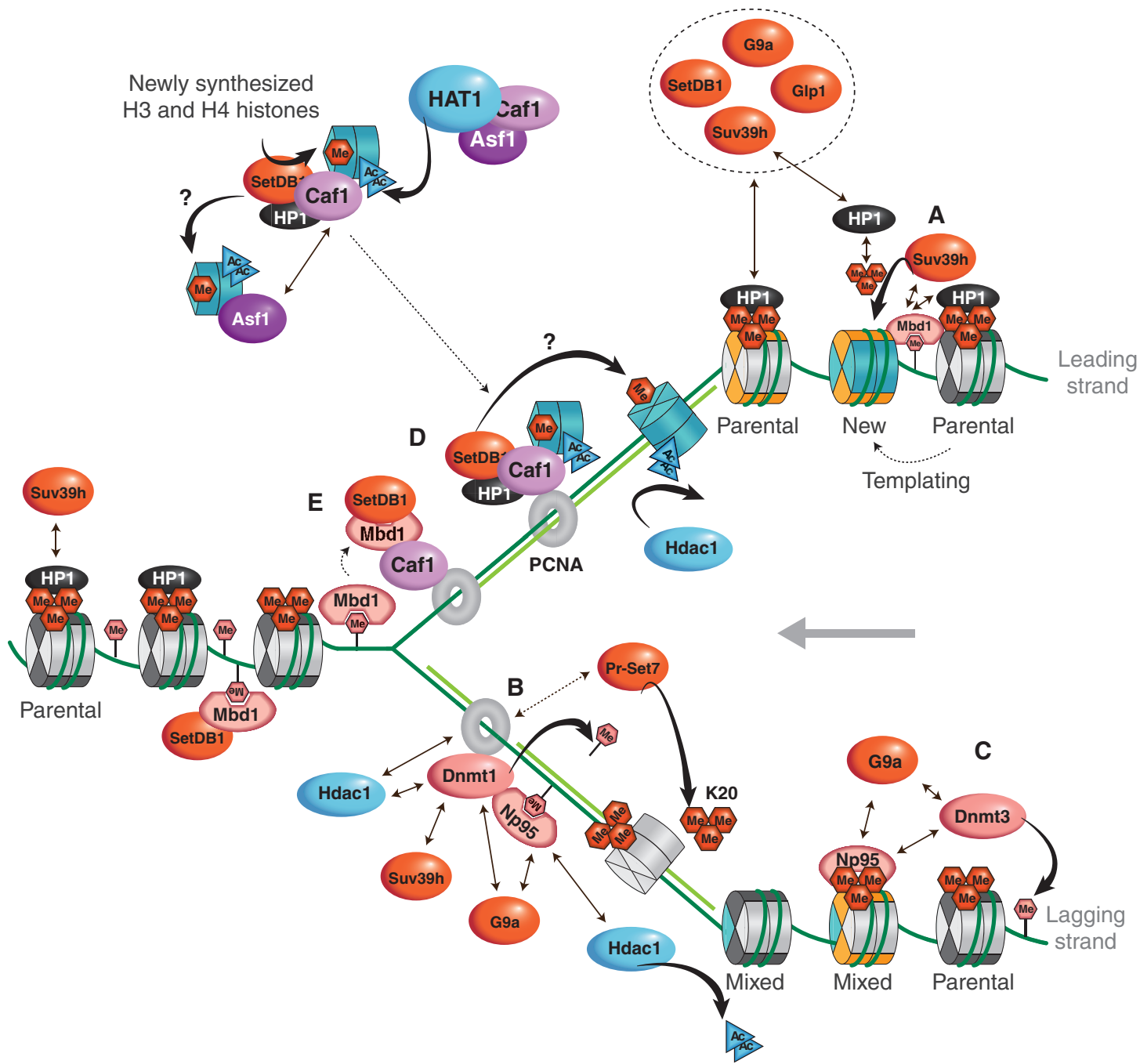

Figure 7. Model for the maintenance of constitutive pericentromeric heterochromatin during chromatin replication in mammals. (A) The maintenance of histone PTMs can be envisioned according to the following mechanism: A parental mark is recognized by a chromatin-binding protein, or reader protein (HP1), which, in turn, recruits a chromatin modifier or writer protein (Suv39h). This writer protein then imposes the parental modification on neighboring new histones (with respect to $\mathrm{H} 3-\mathrm{H} 4$ histones only illustrated in turquoise). This model has been suggested for the feedback loop in the maintenance of HP1 at pericentric heterochromatin or the repressive mark H3K27me3. HP1 binds to H3K9me3 (triangle of red hexagons) through its chromodomain and, in turn, recruits more of the H3K9 methyltransferase Suv39h (KMT1A). Suv39h could then further methylate the de novo assembled $\mathrm{H} 3 \mathrm{~K} 9$ me1-marked nucleosomes into $\mathrm{H} 3 \mathrm{~K} 9 \mathrm{me} 3$. The latter would provide additional binding sites for HP1 $\alpha$ in pericentric heterochromatin. For H3K27me3 maintenance, both the reader and writer modules are part of the same protein, which is PRC2 (Polycomb repressive complex 2). Whether these modifications are immediately imposed on new histones after replication, or this happens at later stages, remains to be investigated. $(B)$ DNA methylation (pink hexagon), histone hypoacetylation, H3K9me3 and H4K20me3 methylation, as well as the enrichment of HP1, propagate during replication of pericentric heterochromatin by exploiting a complex network of histone chaperones and modifiers still under investigation, in which PCNA functions as a central hub. Dnmt1, which is targeted to hemimethylated or $\mathrm{H} 3 \mathrm{~K} 9 \mathrm{me} 3$ sites at replication foci via its interactions with PCNA and Np95, as described in the text, ensures maintenance of DNA methylation. Histone-modifying enzymes G9a and Suv39h can be recruited via their interaction with Dnmt1. (C) In addition, recent data suggest that Dnmt3A/3B could also be involved in maintenance of DNA methylation in highly methylated regions. These enzymes could be targeted by an interaction with the nucleosomes, or indirectly through Np95 or G9a. In this manner, maintenance of DNA and histone methylation can be coordinated. Formation of a multimeric complex between the four histone H3K9 methyltransferases, G9a, Suv39h, GLP (G9a-like protein 1), and SetDB1, could further ensure maintenance of H3K9 methylation states. $(D)$ CAF-1, which can be found in distinct complexes with either $\mathrm{H} 3.1$ or $\mathrm{HP} 1 \alpha$, is also targeted via PCNA to the replication fork. The dual interaction ensures the handling of both histones and HP1 proteins in a successive manner. This could be advantageous to promote redistribution of HP1 proteins at pericentric heterochromatin. $(E)$ Furthermore, the CAF-1 connection with an MBD1-SetDB1 and HP1 $\alpha$-SetDB1 complex could promote H3K9 methylation. Asf1 could participate in this assembly line by docking onto CAF-1 while monomethylation of $\mathrm{H} 3 \mathrm{~K} 9$ is imposed. As a current working hypothesis, this model should help to refine the precise mechanisms and protein interactions involved. Tapered arrows represent catalytic action. Straight arrows signify interactions (dashed when possible interactions). (Adapted from Corpet and Almouzni 2009, with permission from Elsevier.) 
on the monomethylation of H4K20 (Scharf et al. 2009b). Cross talk between histone deacetylation and DNA methylation is also suggested in mouse cells, based on the hyperacetylation of H4K5,K12 observed following Np95 depletion. Np95 is an SRA domain-containing protein (also known as UHRF1 and ICPB90) that binds methylated DNA (Papait et al. 2007). Somehow, Np95 may function in linking DNA methylation maintenance with the proper deacetylation of histone $\mathrm{H} 4$ at heterochromatic regions. Other HDAC interactors, in addition to Np95 itself, include Suv39h1 (KMT1A), Dnmt1, and PCNA (Fig. 7B) (Fuks et al. 2000; Robertson et al. 2000; Milutinovic et al. 2002; Vaute et al. 2002; Unoki et al. 2004). HDACs would, thus, ensure the maintenance of a deacetylated state of chromatin, together with $\mathrm{H} 3 \mathrm{~K} 9 \mathrm{me} 3$, at replication forks in highly histone-methylated heterochromatin regions. On the other hand, in regions in which HDACs are not tightly targeted, it may be easier to maintain acetylated states following the passage of the fork.

With respect to facultative heterochromatin regions, the process proposed for maintaining the $\mathrm{H} 3 \mathrm{~K} 27 \mathrm{me} 3$ histone modification through cell division resembles the one put forward for H3K9me3 (Hansen and Helin 2009; Margueron et al. 2009). Here, PRC2, the very enzyme that catalyzes this modification, directly binds to H3K27me3. Accordingly, it could copy this methylation mark onto neighboring newly incorporated histones (Hansen and Helin 2009; Margueron et al. 2009). PRC1 (Polycomb repressive complex 1) complex, which remains associated with DNA during replication in vitro, could also potentially participate in the maintenance of transcriptional silent states through cell division (Francis et al. 2009). However, whether PRC1 remains in direct contact with DNA during DNA replication or its transfer involves component of the replication machinery remains to be elucidated.

Studies have provided a glimpse of how H4K20 monomethylation could be maintained during DNA replication. Pr-Set7 (also known as Set8 or KMT5A), an H4K20 histone monomethyltransferase, is found at replication sites and required for the progression through $\mathrm{S}$ phase (Jorgensen et al. 2007; Tardat et al. 2007; Huen et al. 2008). The targeting to replication forks could be by direct interaction with PCNA via a "PIP box" (PCNA-interacting protein box) in its amino terminus (Jorgensen et al. 2007; Huen et al. 2008). However, the reported low levels of Pr-Set7 during $S$ phase challenge this view (Oda et al. 2009). Thus, further investigation is needed to reproduce Pr-Set7-catalyzed H4K20 monomethylation patterns on daughter strands via its interaction with PCNA. Nevertheless, the essential role of Pr-Set7 for mouse development (Huen et al. 2008; Oda et al. 2009), associated with its functions in cell division and genome stability (Jorgensen et al. 2007;
Tardat et al. 2007), points to an important function of this enzyme.

\subsubsection{Histone Variants}

Given that histone variants can mark particular chromatin states, a challenging question is to understand how their incorporation is propagated through replication. And, if maintenance is ensured over the cell cycle, how is this achieved? Here, we will use $\mathrm{H} 3$ variants to illustrate how general principles can be derived and potentially applied to other chromatin marks.

A genome-wide distribution is expected for canonical replicative histone variants $\mathrm{H} 3.1$ or H3.2, mainly deposited during replication. However, incorporation of H3.1 occurs outside S phase at sites of UV damage (Polo et al. 2006), therefore, marking a site that has experienced damage, much as a scar marks damaged skin. This may provide a memory of damage, based on newly synthesized histones carrying different PTMs from the original ones. Furthermore, oligonucleosomes containing H3.1 are more prominently associated with $\mathrm{HP} 1 \alpha$ and MBD1, suggesting an enrichment of H3.1 in constitutive pericentric heterochromatin (Loyola et al. 2006). These domains of concentration could reflect a default state if no other variant gets incorporated outside $S$ phase. This is consistent with the fact that replacement variant H3.3 accumulates in actively transcribed chromatin regions, as first shown in Drosophila (Ahmad and Henikoff 2002) and within chromatin enriched in "active" marks when compared with the replicative variants (McKittrick et al. 2004; Hake et al. 2006; Loyola et al. 2006). Histone H3.3 accumulation at promoters of active genes or regulatory elements may exploit a replication-independent mechanism involving the histone chaperone HIRA (Henikoff and Smith 2014). Although, during replication, the dilution of active marks on parental histones occurs, the amount provided may be sufficient to maintain a permissive state for transcription, which, in turn, would add more active marks. The presence of some H3.3 along with active marks would thus act as a seeding event. According to this view, the memory of an active transcriptional state could therefore involve both the choice of the H3.3 variant combined with an active mark, such as H3K4 methylation (Ng and Gurdon 2008; Muramoto et al. 2010). However, not only is H3.3 confined to sites of active transcription, but it can also be enriched in other genomic regions depending on the developmental context. At the time of fertilization, a massive and global accumulation of H3.3 occurs on sperm-derived DNA (Loppin et al. 2005) and, in ES cells, H3.3 accumulates at telomeres (illustrated in Fig. 10 of Allis et al. 2014) (Goldberg et al. 2010; Wong et al. 2010). How these events are 
controlled and which factors are involved are beginning to be unraveled (for review, see Maze et al. 2014). It is amazing, nevertheless, to bear in mind that $\mathrm{H} 3.1, \mathrm{H} 3.2$, and $\mathrm{H} 3.3$ show very little sequence difference; thus, how specificity in their deposition is achieved remains a fascinating but unresolved issue.

In contrast to H3.3, CENP-A is highly divergent (Wolffe and Pruss 1996). It provides the best example of a histone H3 variant that specifies a functional locus: the site of centromere identity (Warburton et al. 1997), which serves as a platform for kinetochore assembly (elaborated in Allshire and Ekwall 2014). During replication of centromeric chromatin, CENP-A nucleosomes become diluted to half the initial concentration on daughter chromatin (Shelby et al. 2000; Jansen et al. 2007). It is not until the next $G_{1}$ phase that new CENP-A gets incorporated again (Fig. 3) (Jansen et al. 2007; Schuh et al. 2007). This case illustrates a situation in which the disruption during replication is clearly separated from the reassembly event outside $S$ phase. HJURP (Holliday junction recognition protein) was discovered to be a CENP-A chaperone, localized at centromeres precisely from late telophase to early $\mathrm{G}_{1}$, promoting the specific targeting/incorporation and maintenance of CENP-A at centromeres (Fig. 3) (Dunleavy et al. 2009; Foltz et al. 2009).

An alternative view of the cell-cycle-regulated assembly of CENP-A chromatin is that incorporation of CENP-A in $G_{1}$ may be programmed in anticipation of the disruptive event during replication, rather than being a restoration of half the pool of CENP-A. Whichever way one looks at this issue, it provides a general conceptual framework for the mechanism by which chromatin marks can be dealt with during the cell cycle. Thus, it is informative to consider how and when histone PTMs or histone variants are actually imposed at particular domains, given that parental nucleosomes experience the disruption caused by passage of the replication fork.

Late steps in chromatin restoration may await reinitiation of transcription on daughter strands as recently proposed for $\mathrm{H} 3 \mathrm{~K} 9 \mathrm{me} 2$ at heterochromatic repeats in Schizosaccharomyces pombe (Chen et al. 2008; Kloc and Martienssen 2008). Similarly, in human cells, di- or trimethylation of $\mathrm{H} 3 \mathrm{~K} 27$ and $\mathrm{H} 4 \mathrm{~K} 20$ has been detected during the next $G_{1}$ phase (Scharf et al. 2009a). This suggests that restoration of global levels of these histone modifications would occur mostly just before the next $\mathrm{S}$ phase, which could be regarded, again, as an anticipation of the dilution event occurring during replication. Thus, our understanding of the transmission of chromatin-based information in a replication-independent manner, concerning the histone $\mathrm{H} 3$ variants and specific PTMs, represents a general theme that may also help to understand the fate of other marks, like association of nuclear RNA, Polycomb proteins, or other chromatin proteins.

\subsection{Summary}

Thus, in eukaryotic cells, chromatin duplication entails a series of complex and coordinated events. These include nucleosomal disruption, histone transfer, and deposition, along with dynamic histone modifications that occur in a manner that maintains particular marks at defined chromatin regions. Chromatin remodelers and histone modifiers and chaperones are critical for chromatin duplication, both at the level of histone dynamics and in the context of reestablishing marks that define distinct chromatin states. It should be noted that replication has also been considered as a window of opportunity important to induce changes in chromatin states (Weintraub 1974). In addition, nonreplicative chromatin dynamics can also promote the maintenance of particular marks, as exemplified with the case of the histone variants H3.3 and CENP-A. To finely tune the balance between maintenance and plasticity during development, these processes are tightly controlled. A better understanding of the fine-tuning of this system and its network of partners not only will improve our basic knowledge of chromatin duplication, but also will be informative with respect to functional conservation between species and will help to gain insight into developmental diseases, as well as cancer.

\section{REPLICATION TIMING}

\subsection{Patterns of Replication Timing}

One of the least understood chromosomal epigenetic marks is DNA replication timing. The entire genome is replicated according to a predetermined program: Some regions replicate early in $S$, others during the middle of $S$, and, yet, other defined loci undergo replication only in late $S$ phase. This pattern can be observed in dividing cells by labeling them with BrdU (bromodeoxyuridine) for fixedtime intervals and then visualizing the incorporated nucleotides in metaphase chromosomes using specific antibodies to BrdU (Hand 1978). The appearance of a clear-cut banding pattern on each individual metaphase chromosome nicely shows that this property is regulated at the regional level. Furthermore, comparative studies indicate that these replication zones actually correspond almost one-to-one with the Giemsa staining pattern in which dark G-bands represent the late-replicating regions (Holmquist 1988). Thus, it appears that chromosomes are organized into distinct subunits, each with its own structure and replication-timing properties. 
Replication timing of individual genes can be measured by using this same labeling approach. After separating cells at different stages of $S$ phase, it is possible to use polymerase chain reaction to detect specific genes in BrdU-labeled DNA. These studies have shown that there is a clear-cut correlation between gene repression and late replication. Active genes tend to replicate early in S phase, whereas inactive genes replicate late. Also, many developmentally regulated and tissue-specific genes are early replicating in the tissue of expression, but late replicating in all other cell types (Holmquist 1987). Although these experiments were originally performed on a small number of individual gene regions, recent genome-wide techniques have confirmed that this is, indeed, a general phenomenon (FarkashAmar and Simon 2010).

Although there is, as yet, no direct proof that replication timing itself can influence gene expression, the fact that this mark is present from the earliest stages of development, as well as its regional nature, both suggest that it is set up independently of transcription and can be maintained in a stable manner. To gain some insight into the mechanisms involved in controlling replication timing, it is necessary to understand the overall scheme of this temporal epigenetic device. Replication is initiated at small DNA regions that are referred to as origins and, in general, DNA synthesis proceeds in a bidirectional manner that radiates from these sites. The determination of when in $\mathrm{S}$ phase each origin is fired appears to be under the control of nearby cis-acting sequences (Raghuraman et al. 1997; Ferguson et al. 1991; Ofir et al. 1999). In animal cells that have large genomes, the initiation of replication often occurs in a regional manner with multiple origins making up a cluster that is programmed to fire simultaneously in a coordinated fashion (Huberman and Riggs 1966, 1968), thus generating a large replication time zone (or band).

\subsection{The Regulation of Replication Timing}

The regulation of this replication-timing process must involve multiple molecular factors. Experiments in both yeast and animal cells indicate that the replication time of each zone is set up during early $\mathrm{G}_{1}$ phase soon after nuclear reorganization (Raghuraman et al. 1997; Dimitrova and Gilbert 1999), and this is evidently accomplished by the recognition of cis-acting elements, which then inform each origin of when in $S$ it should be fired. The human $\beta$-globin locus provides a good example for how this might work. The $\beta$-globin gene, together with its neighboring developmental paralogs, are imbedded in a gene region of $\sim 100 \mathrm{~kb}$ that replicates late in almost all cell types, but becomes early replicating in erythroid lineage cells (Dhar et al. 1988). Both early and late replication are initiated by a single bidirectional origin located adjacent to the $\beta$-globin gene promoter (Kitsberg et al. 1993b; Aladjem et al. 1998).

Using a large bacterial artificial chromosome (BAC) transgene containing the full human $\beta$-globin domain, it has been shown that the locus control region (LCR) positioned upstream of the globin gene array plays a cis-acting role in mediating replication timing (Simon et al. 2001). When the full LCR is present, this entire gene region replicates late in most tissues, but early in erythroid tissues, regardless of its site of integration in the genome. Mutations in the regulatory unit, however, can severely affect this pattern (Forrester et al. 1990), thereby causing the transgene to lose its dominance and, thus, come under replication-timing control of surrounding endogenous sequences. These studies suggest that this multifunctional cis-acting domain affects both early and late time settings of the single origin sequence controlling this region. It is very likely that time zones, in general, are set up by long-range cis-acting sequences of this nature, which serve as recognition sites for cell-type-specific trans-acting factors.

Although little is known about the protein factors that participate in this process, a number of different studies have highlighted their existence. Fusion of lymphoid with erythroid cells, for example, causes the globin domain in this nonerythroid nucleus to undergo a dramatic switch from late to early replication, probably because of its exposure to a new set of factors that reset the timing mechanism (Forrester et al. 1990). Another striking example of the role of transacting factors is the reprogramming of replication timing that takes place during SCNT (somatic cell nuclear transfer). A number of specific gene regions have been shown to be early replicating in the early embryo, but become late replicating in all somatic cells following implantation (Hiratani et al. 2004; Perry et al. 2004). Interestingly, when a somatic cell nucleus is transplanted to fertilized oocyte cells, these same regions rapidly revert back to the early replication pattern, and this occurs almost immediately during the first division cycle. Other gene regions switch replication from early to late $S$ phase following nuclear transplantation (Shufaro et al. 2010). These experiments clearly show that replication timing is dependent on the presence of local transacting factors, which apparently have a role in setting up the proper time slot for DNA synthesis during each passage through the cell cycle.

What is the mechanism by which these cis-acting control centers influence the firing of local origins? Very elegant studies in yeast were the first to show that the time of replication initiation may be influenced by histone acetylation at the origin sequence (Fig. 8A) (Vogelauer et al. 2002). When histones located at a late-replicating origin were forcibly acetylated, this had the effect of changing the firing time to an early slot. In a similar manner, removal 


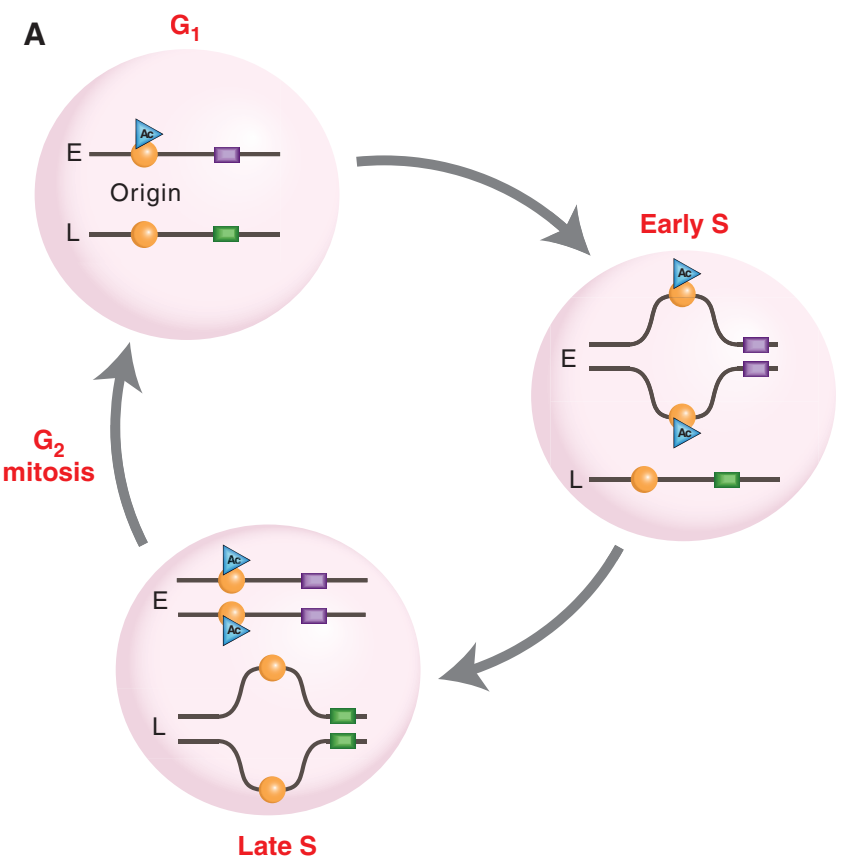

B



Early S

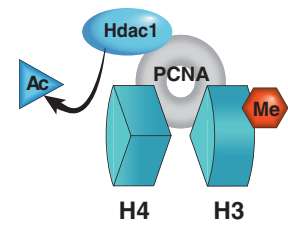

Late S

Figure 8. Regulation of replication timing. (A) The diagram shows two different DNA regions, one that replicates early $(\mathrm{E})$ in $S$ phase and one that replicates late $(\mathrm{L})$. In $\mathrm{G}_{1}$, histones packaging the early-replicating origin (orange circle) become acetylated because trans-acting factors in the cell recognize specific "early" cis-acting sequences (purple rectangle). In contrast, nucleosomes packaging the late-replicating origin are prevented from becoming acetylated by virtue of different $c i s$-acting motifs (green). During early $\mathrm{S}$ phase, protein factors specific for this stage in the cell cycle recognize acetylated origins and initiate the process of replication. Unacetylated origins remain unreplicated. Finally, factors specific for late $S$ phase recognize and initiate firing of unacetylated origins, bringing about replication of late-replicating DNA regions. $(B)$ Replication origins that are marked with acetylated histones $\mathrm{H} 3$ and $\mathrm{H} 4$ replicate early in $\mathrm{S}$ phase, whereas the deacetylation of origin regions primes them for late replication in $\mathrm{S}$ phase.

of acetylation at an origin caused it to initiate replication late. More recent studies have shown that this same mechanism may also play a role in the control of replication timing in animal cells (Goren et al. 2008). The human globin domain origin, for example, is packaged with acetylated histones in erythroid cells in which it replicates early, whereas the exact same origin is deacetylated in nonerythroid cells. This pattern is recapitulated on a transgene containing the full human $\beta$-globin locus. Strikingly, tethering

a histone acetylase to the origin region caused this domain to switch from late to early replication in nonerythroid cells of the mouse, and, in a parallel manner, forced deacetylation in vivo caused the globin domain to become abnormally late replicating in erythroid cells (Fig. 8B).

\subsection{Cause or Effect?}

Despite the clear-cut correlation between early replication timing and gene expression, little is known about the mechanistic connection between these two parameters. It does not appear that replication timing comes about as a direct result of local expression patterns because changes in expression do not automatically bring about replicationtiming shifts (Cimbora et al. 2000; Simon et al. 2001; Farkash-Amar et al. 2008). Given that replication time zones are very large, often encompassing many gene sequences, it follows that replication timing is unlikely to be dictated by gene expression. In contrast, there does seem to be some evidence for the opposite idea that replication timing itself may influence histone modification and gene expression patterns.

An experiment testing the influence of replication timing on histone marks and gene expression involved the nuclear microinjection of reporter plasmids directly into early S-phase nuclei. Plasmids injected into early S-phase nuclei become packaged in an acetylated histone structure, whereas these same templates get assembled with deacetylated histones when introduced into cells during late $S$ phase (Zhang et al. 2002). Furthermore, DNA that is already in a deacetylated chromatin structure becomes acetylated when it undergoes subsequent replication in early $\mathrm{S}$, whereas templates carrying acetylated histones switch to a deacetylated state after replication in late S (Rountree et al. 2000; Lande-Diner et al. 2009). During the normal DNA replication cycle in vivo, preexisting histones on the original template DNA segregate randomly to both sister molecules, and new histones are then added to regenerate the original nucleosome-packing density (Lucchini and Sogo 1995). These new nucleosomes may be assembled in either an acetylated or a deacetylated form. The experiments described above strongly suggest that different regions of the DNA get repackaged, depending on their time of replication. Early-replicating DNA appears to incorporate nucleosomes that adopt an acetylated form, whereas late-replicating regions get repackaged with deacetylated nucleosomes, thus, transiently generating large chromosome domains that have a relatively uniform histone modification pattern (Fig. 8A).

Because these events take place through the action of histone modification and demodification enzymes that are closely associated with the dynamically progressing 
replication fork machinery, this does not constitute a reliable mechanism for maintaining these acetylation states throughout the cycle, and it is likely that this overall pattern may undergo further adjustments through the action of locally acting histone-marking enzymes recruited to specific sites on the DNA. It, thus, appears that zonal replicationtiming control provides a crude system for setting up general background structure following DNA synthesis so that active chromosomal bands are assembled with acetylated histones, whereas more inactive zones are initially packaged with deacetylated histones. This mechanism would help make the task of postreplication reassembly much more efficient. According to this scheme, replication timing represents a type of ground-state maintenance mechanism that helps recreate the original chromatin structure following DNA synthesis.

Because the replication-banding pattern, as observed on mitotic chromosomes, appears to be extremely stable throughout development, it is likely that this epigeneticmarking system may have an autonomous maintenance system, which insures that the original timing pattern after each round of replication is restored. The histone acetylation pattern of nucleosomes at origin sequences may provide a simple system for such a maintenance scheme. As noted above, origins marked by histone acetylation fire early in S phase, whereas those that are packaged with deacetylated histones are instructed to skip the early times and only fire in late $S$ phase (Fig. 8). Following activation of the origin, this same region then undergoes partial reassembly to fill in missing nucleosomes. Because of differences in the packaging machinery present at the replication fork in early as opposed to late $S$ phase means that early origins will continue to be in an acetylated conformation, whereas those that fire late will once again acquire histones that are deacetylated. This clearly represents an elegant maintenance mechanism for autonomously preserving replication-timing patterns from one cell generation to the next (Fig. 8A).

Replication time slots are thought to be set up in the $G_{1}$ phase of each cycle (Raghuraman et al. 1997; Dimitrova and Gilbert 1999), probably through interactions of trans-acting factors with cis-acting control sequences that ultimately lead to the setting up of appropriate acetylation patterns over adjacent origins that are under their command (Vogelauer et al. 2002; Goren et al. 2008). Furthermore, it appears that changes in these factors can act very quickly to reset the timing pattern (Forrester et al. 1990; Shufaro et al. 2010). With this in mind, it may be best to view replication time maintenance as being governed by two separate parameters; the autonomous cis-acting acetylated system is backed up by a trans-acting mechanism that can, if necessary, reset the timing switches to their proper mode.

\subsection{Asynchronous Replication Timing}

Although most chromosome regions replicate at the same time on both parental alleles, $>10 \%$ of the genome appears to replicate asynchronously with one allele undergoing DNA synthesis early, whereas the other gets copied late in S phase (Farkash-Amar and Simon 2010). This can be visualized by fluorescence in situ hybridization of such a gene in cells fixed midway through $S$ phase in which two dots represent the replicated allele and one dot represents the unreplicated allele. There appear to be two different paradigms for this behavior, and both of them are associated with monoallelic gene expression patterns. Imprinted genes are examples of one paradigm for asynchronous replication; the alleles of such gene clusters replicate asynchronously in every somatic cell, although they are all embedded within large chromosomal domains (Kitsberg et al. 1993a). For example, a paternal allele could be set up to be early replicating during late spermatogenesis, and remains this way in the early preimplantation embryo and then throughout development (Simon et al. 1999). In a complementary manner, the maternal, often repressed, allele is set up to be late replicating during final stages of oogenesis. This pattern is maintained in all cells regardless of the imprinted gene expression patterns on the two alleles. It is commonly assumed that allele-specific methylation patterns in somatic cells are responsible for preserving the identity of each allele separately. However, parental identity can also be maintained in the absence of any DNA methylation marks, both during late gametogenesis (Perk et al. 2002; Reik and Walter 2001) and in the very early embryo (Birger et al. 1999). It is possible that asynchronous replication timing may play a role in this process, specifically during these stages of development.

Another paradigm for asynchronous replication occurs at a large number of chromosomal domains that are not imprinted. In these cases, one parental allele in each cell is early, whereas the other replicates late. In 50\% of the cells, it is the maternal allele that replicates early, whereas, in other cells, it is the paternal allele that is copied first in S phase (Goren and Cedar 2003). These loci appear to initially replicate synchronously in the preimplantation embryo, but then become asynchronous at about the time of implantation when the embryo begins to undergo differentiation (Mostoslavsky et al. 2001). Once the decision is made as to which allele will be early, this pattern is then maintained in a clonal manner (Singh et al. 2003). This form of asynchronous replication is often associated with allelic choice. Antigen receptor arrays, like those at the $\kappa, \mu$, or T-cell receptor (TCR) $\beta$ loci, for example, are all positioned within asynchronous replicating domains (Mostoslavsky et al. 2001). During the process of antigen receptor selec- 
tion, the primary rearrangement event always occurs preferentially on the early replicating allele, and this evidently serves as a first-line basis for allelic exclusion, a process that insures that only a single receptor is selected in each individual cell (see Busslinger and Tarakhovsky 2014 for more detail). Although there is no evidence showing that replication timing itself is directly involved in this selection process, there is no question that it represents an early marker for predicting allelic choice.

Olfactory receptors are also organized in a similar manner, with each cluster in the genome undergoing asynchronous replication, and here, too, there is a mechanism of allelic exclusion that restricts receptor choice to a single allele in each olfactory neuron (elaborated in Lomvardas and Maniatis 2014). Because, in both of these systems, the activation of individual gene segments within each cluster is stochastic, it is allelic exclusion that actually facilitates the selection of only a single gene in each cell. In this sense, asynchronous replication appears to be part of the regulatory machinery that promotes gene diversity in the organism's ability to interact with its environment. Other examples of asynchronous replication and allelic exclusion include the recombinant DNA loci, which are only expressed from a single allele in each cell (Schlesinger et al. 2009) and, of course, the $X$ chromosome in females, in which inactivation of one entire chromosome is associated with late replication timing (Brockdorff and Turner 2014).

The finding that asynchronous replication timing at certain loci in the genome can be inherited in a clonal manner strongly suggests that there must be an autonomous mechanism for maintaining replication-timing patterns. This is especially poignant in light of the fact that each allele is capable of independently maintaining its differential timing profile for many cell generations. It should be noted that numerous asynchronous replication domains are located on each chromosome where they are dispersed among large intervening regions that replicate both alleles synchronously. Strikingly, on any individual chromosome, all of these loci appear to replicate in a coordinated manner (Singh et al. 2003; Ensminger and Chess 2004). On chromosome 6 in the mouse, for example, in cells that have the $\kappa$ locus early replicating on one allele, the TCR $\beta$ locus on the same chromosome is also early replicating, and the same is true for additional asynchronous markers in cis. This suggests that asynchronous replication timing is actually controlled by central regulatory units that operate chromosome wide. Thus, any maintenance mechanism must be focused on these master regulatory sequences, and it is very possible that this mechanism may be based on other epigenetic markers, such as DNA methylation, which is known to have its own autonomous maintenance scheme.

\section{CONCLUSIONS}

Unravelling how epigenetic marks are inherited from one somatic generation to the next has been a key endeavor in epigenetic research for decades. We now know the many molecules involved in the process. The specifics, however, of how the inheritance of marks is orchestrated through the cell cycle still has many unanswered questions. This article first looks at how DNA methylation provides an autonomous mechanism for the propagation of a mark that is largely involved in gene repression. As research has delved more into investigating how the marks placed on histones in a chromatin context are inherited, we have discovered the involvement of histone chaperones, readers, nucleosome remodelers, and chromatin-modifying enzymes, which are inextricably linked with the DNA replication machinery. We have gained an understanding of how histone synthesis is cell-cycle-regulated, depending on the type of histone, in order to cater for the demand of new histones required in chromatin assembly. Their PTM before chromatin assembly may aid in assembling context appropriate chromatin. Concerning the dynamics of chromatin duplication, we present current models consistent with the available data on histone recycling or de novo introduction during the process of nucleosome disruption, transfer, and deposition at the replication fork. Likewise, the mechanisms of histone mark propagation on the chromatin template at other stages of the cell cycle are discussed. Last, our knowledge of how replication timing during $\mathrm{S}$ phase seems to present another layer in the epigenetic toolbox of mechanisms used to distinguish or even specify and ensure the propagation of chromatin states at the level of large genomic domains is discussed. Further research is still needed to understand how this intersects with other epigenetic marks in the maintenance or change of epigenomic specification through the cell cycle.

\section{ACKNOWLEDGMENTS}

This work was supported by la Ligue Nationale contre le Cancer (G.A.), the European Commission Network of Excellence EpiGeneSys (G.A.), the European Research Council (H.C. and G.A.), the Agence Nationalc de la Recherche (ANR) (G.A.), the Israel Science Foundation (H.C.), Lew Sanders (H.C.), and Norton Herrick (H.C.).

\section{REFERENCES}

* Reference is also in this subject collection.

Aagaard L, Laible G, Selenko P, Schmid M, Dorn R, Schotta G, Kuhfittig S, Wolf A, Lebersorger A, Singh PB, et al. 1999. Functional mammalian homologues of the Drosophila PEV-modifier Su(var)3-9 encode centromere-associated proteins which complex with the heterochromatin component M31. EMBO J 18: 1923-1938. 
Agalioti T, Chen G, Thanos D. 2002. Deciphering the transcriptional histone acetylation code for a human gene. Cell 111: 381-392.

Ahmad K, Henikoff S. 2002. The histone variant H3.3 marks active chromatin by replication-independent nucleosome assembly. Mol Cell 9: $1191-1200$.

Aladjem MI, Rodewald LW, Kolman JL, Wahl GM. 1998. Genetic dissection of a mammalian replicator in the human $\beta$-globin locus. Science 281: $1005-1009$.

* Allis CD, Jenuwein T, Reinberg D. 2014. Overview and concepts. Cold Spring Harb Perspect Biol doi: 10.1101/cshperspect.a018739.

* Allshire RC, Ekwall K. 2014. Epigenetic regulation of chromatin states in Schizosaccharomyces pombe. Cold Spring Harb Perspect Biol doi: 10.1101/cshperspect.a018770.

Annunziato AT. 2005. Split decision: What happens to nucleosomes during DNA replication? J Biol Chem 280: 12065-12068.

Bannister AJ, Zegerman P, Partridge JF, Miska EA, Thomas JO, Allshire RC, Kouzarides T. 2001. Selective recognition of methylated lysine 9 on histone H3 by the HP1 chromo domain. Nature 410: 120-124.

* Barlow DP, Bartolomei MS. 2014. Genomic imprinting in mammals. Cold Spring Harb Perspect Biol 6: a018382.

* Baylin SB, Jones PA. 2014. Epigenetic determinants of cancer. Cold Spring Harb Perspect Biol doi: 10.1101/cshperspect.a019505.

Baxevanis AD, Godfrey JE, Moudrianakis EN. 1991. Associative behavior of the histone (H3-H4)2 tetramer: Dependence on ionic environment. Biochemistry 30: 8817-8823.

* Becker PB, Workman JL. 2013. Nucleosome remodeling and epigenetics. Cold Spring Harb Perspect Biol 5: a017905.

Bhaskara S, Chyla BJ, Amann JM, Knutson SK, Cortez D, Sun ZW, Hiebert SW. 2008. Deletion of histone deacetylase 3 reveals critical roles in S phase progression and DNA damage control. Mol Cell 30: $61-72$.

Birger Y, Shemer R, Perk J, Razin A. 1999. The imprinting box of the mouse Igf2r gene. Nature 397: 84-88.

Brandeis M, Frank D, Keshet I, Siegfried Z, Mendelsohn M, Nemes A, Temper V, Razin A, Cedar H. 1994. Sp1 elements protect a CpG island from de novo methylation. Nature 371: 435-438.

* Brockdorff N, Turner BM. 2014. Dosage compensation in mammals. Cold Spring Harb Perspect Biol doi: 10.1101/cshperspect.a019406.

* Busslinger M, Tarakhovsky A. 2014. Epigenetic control of immunity. Cold Spring Harb Perspect Biol 6: a019307.

Chen ES, Zhang K, Nicolas E, Cam HP, Zofall M, Grewal SI. 2008. Cell cycle control of centromeric repeat transcription and heterochromatin assembly. Nature 451: 734-737.

* Cheng X. 2014. Structural and functional coordination of DNA and histone methylation. Cold Spring Harb Perspect Biol 6: a018747.

Cimbora DM, Schubeler D, Reik A, Hamilton J, Francastel C, Epner EM, Groudine M. 2000. Long-distance control of origin choice and replication timing in the human $\beta$-globin locus are independent of the locus control region. Mol Cell Biol 20: 5581-5591.

Cloos PA, Christensen J, Agger K, Helin K. 2008. Erasing the methyl mark: Histone demethylases at the center of cellular differentiation and disease. Genes Dev 22: 1115-1140.

Corpet A, Almouzni G. 2009. Making copies of chromatin: The challenge of nucleosomal organization and epigenetic information. Trends Cell Biol 19: 29-41.

Dalal Y, Wang H, Lindsay S, Henikoff S. 2007. Tetrameric structure of centromeric nucleosomes in interphase Drosophila cells. PLoS Biol 5: e218.

Das C, Lucia MS, Hansen KC, Tyler JK. 2009. CBP/p300-mediated acetylation of histone $\mathrm{H} 3$ on lysine 56. Nature 459: 113-117.

Dhar V, Mager D, Iqbal A, Schildkraut CL. 1988. The coordinate replication of the human $\beta$-globin gene domain reflects its transcriptional activity and nuclease hypersensitivity. Mol Cell Biol 8: 4958-4965.

Dimitrova DS, Gilbert DM. 1999. The spatial position and replication timing of chromosomal domains are both established in early $\mathrm{G}_{1}$ phase. Mol Cell 4: 983-993.
Dunleavy EM, Roche D, Tagami H, Lacoste N, Ray-Gallet D, Nakamura Y, Daigo Y, Nakatani Y, Almouzni-Pettinotti G. 2009. HJURP is a cellcycle-dependent maintenance and deposition factor of CENP-A at centromeres. Cell 137: 485-497.

Eden S, Hashimshony T, Keshet I, Thorne AW, Cedar H. 1998. DNA methylation models histone acetylation. Nature 394: 842-843.

Ekwall K, Olsson T, Turner BM, Cranston G, Allshire RC. 1997. Transient inhibition of histone deacetylation alters the structural and functional imprint at fission yeast centromeres. Cell 91: 1021-1032.

English CM, Adkins MW, Carson JJ, Churchill ME, Tyler JK. 2006. Structural basis for the histone chaperone activity of Asf1. Cell 127: 495508.

Ensminger AW, Chess A. 2004. Coordinated replication timing of monoallelically expressed genes along human autosomes. Hum Mol Genet 13: $651-658$.

Farkash-Amar S, Simon I. 2010. Genome-wide analysis of the replication program in mammals. Chromosome Res 18: 115-125.

Farkash-Amar S, Lipson D, Polten A, Goren A, Helmstetter C, Yakhini Z, Simon I. 2008. Global organization of replication time zones of the mouse genome. Genome Res 18: 1562-1570.

Feldman N, Gerson A, Fang J, Li E, Zhang Y, Shinkai Y, Cedar H, Bergman Y. 2006. G9a-mediated irreversible epigenetic inactivation of Oct-3/4 during early embryogenesis. Nat Cell Biol 8: 188-194.

Ferguson BM, Brewer BJ, Reynolds AE, Fangman WL. 1991. A yeast origin of replication is activated late in S phase. Cell 65: 507-515.

Finn RM, Browne K, Hodgson KC, Ausio J. 2008. sNASP, a histone H1specific eukaryotic chaperone dimer that facilitates chromatin assembly. Biophys J 95: 1314-1325.

Foltz DR, Jansen LE, Bailey AO, Yates JR 3rd, Bassett EA, Wood S, Black BE, Cleveland DW. 2009. Centromere-specific assembly of CENP-a nucleosomes is mediated by HJURP. Cell 137: 472-484.

Forrester WC, Epner E, Driscoll MC, Enver T, Brice M, Papayannopoulou T, Groudine M. 1990. A deletion of the human $\beta$-globin locus activation region causes a major alteration in chromatin structure and replication across the entire $\beta$-globin locus. Genes Dev 4: 1637-1649.

Francis NJ, Follmer NE, Simon MD, Aghia G, Butler JD. 2009. Polycomb proteins remain bound to chromatin and DNA during DNA replication in vitro. Cell 137: 110-122.

Fritsch L, Robin P, Mathieu JR, Souidi M, Hinaux H, Rougeulle C, HarelBellan A, Ameyar-Zazoua M, Ait-Si-Ali S. 2010. A subset of the histone H3 lysine 9 methyltransferases Suv39h1, G9a, GLP, and SETDB1 participate in a multimeric complex. Mol Cell 37: 46-56.

Fujita N, Watanabe S, Ichimura T, Tsuruzoe S, Shinkai Y, Tachibana M, Chiba T, Nakao M. 2003. Methyl-CpG binding domain 1 (MBD1) interacts with the Suv39h1-HP1 heterochromatic complex for DNA methylation-based transcriptional repression. J Biol Chem 278: 24132-24138.

Fuks F, Burgers WA, Brehm A, Hughes-Davies L, Kouzarides T. 2000. DNA methyltransferase Dnmtl associates with histone deacetylase activity. Nat Genet 24: 88-91.

Garcia BA, Hake SB, Diaz RL, Kauer M, Morris SA, Recht J, Shabanowitz J, Mishra N, Strahl BD, Allis CD, et al. 2007. Organismal differences in post-translational modifications in histones $\mathrm{H} 3$ and H4. J Biol Chem 282: $7641-7655$.

Gasser R, Koller T, Sogo JM. 1996. The stability of nucleosomes at the replication fork. J Mol Biol 258: 224-239.

Gerard A, Koundrioukoff S, Ramillon V, Sergere JC, Mailand N, Quivy JP, Almouzni G. 2006. The replication kinase Cdc7-Dbf4 promotes the interaction of the p150 subunit of chromatin assembly factor 1 with proliferating cell nuclear antigen. EMBO Rep 7: 817-823.

Goldberg AD, Banaszynski LA, Noh KM, Lewis PW, Elsaesser SJ, Stadler S, Dewell S, Law M, Guo X, Wen D, et al. 2010. Distinct factors control histone variant H3.3 localization at specific genomic regions. Cell 140: 678-691.

Goren A, Cedar H. 2003. Replicating by the clock. Nat Rev Mol Cell Biol 4: $25-32$. 
Goren A, Simchen G, Fibach E, Szabo PE, Tanimoto K, Chakalova L, Pfeifer GP, Fraser PJ, Engel JD, Cedar H. 2006. Fine tuning of globin gene expression by DNA methylation. PLOS ONE 1: e46.

Goren A, Tabib A, Hecht M, Cedar H. 2008. DNA replication timing of the human $\beta$-globin domain is controlled by histone modification at the origin. Genes Dev 22: 1319-1324.

Groth A, Ray-Gallet D, Quivy JP, Lukas J, Bartek J, Almouzni G. 2005. Human Asf1 regulates the flow of $S$ phase histones during replicational stress. Mol Cell 17: 301-311.

Groth A, Corpet A, Cook AJ, Roche D, Bartek J, Lukas J, Almouzni G. 2007a. Regulation of replication fork progression through histone supply and demand. Science 318: 1928-1931.

Groth A, Rocha W, Verreault A, Almouzni G. 2007b. Chromatin challenges during DNA replication and repair. Cell 128: 721-733.

Gruenbaum Y, Naveh-Many T, Cedar H, Razin A. 1981. Sequence specificity of methylation in higher plant DNA. Nature 292: 860-862.

Gruenbaum Y, Cedar H, Razin A. 1982. Substrate and sequence specificity of a eukaryotic DNA methylase. Nature 295: 620-622.

Gunjan A, Verreault A. 2003. A Rad53 kinase-dependent surveillance mechanism that regulates histone protein levels in S. cerevisiae. Cell 115: $537-549$.

Gunjan A, Paik J, Verreault A. 2005. Regulation of histone synthesis and nucleosome assembly. Biochimie 87: 625-635.

Gurard-Levin ZA, Quivy JP, Almouzni G. 2014. Histone chaperones: Assisting histone traffic and nucleosome dynamics. Annu Rev Biochem 83: 487-517.

Hake SB, Garcia BA, Duncan EM, Kauer M, Dellaire G, Shabanowitz J, Bazett-Jones DP, Allis CD, Hunt DF. 2006. Expression patterns and post-translational modifications associated with mammalian histone H3 variants. J Biol Chem 281: 559-568.

Hand R. 1978. Eucaryotic DNA: Organization of the genome for replication. Cell 15: 317-325.

Hansen KH, Helin K. 2009. Epigenetic inheritance through self-recruitment of the polycomb repressive complex 2. Epigenetics 4: 133-138.

Hashimshony T, Zhang J, Keshet I, Bustin M, Cedar H. 2003. The role of DNA methylation in setting up chromatin structure during development. Nat Genet 34: 187-192.

* Henikoff S, Smith MM. 2014. Histone variants and epigenetics. Cold Spring Harb Perspect Biol doi: 10.1101/cshperspect.a019364.

Hiratani I, Leskovar A, Gilbert DM. 2004. Differentiation-induced replication-timing changes are restricted to AT-rich/long interspersed nuclear element (LINE)-rich isochores. Proc Natl Acad Sci 101: $16861-16866$.

* Hochedlinger K, Jaenisch R. 2014. Induced pluripotency and epigenetic reprogramming. Cold Spring Harb Perspect Biol doi: 10.1101/ cshperspect.a019448.

Hoek M, Stillman B. 2003. Chromatin assembly factor 1 is essential and couples chromatin assembly to DNA replication in vivo. Proc Natl Acad Sci 100: 12183-12188.

Holmquist GP. 1987. Role of replication time in the control of tissue specific gene expression. Am J Hum Genet 40: 151-173.

Holmquist G. 1988. DNA sequences in G-bands and R-bands. In Chromosomes and chromatin (ed. Adolph KW), pp. 75-121. CRC Press, Boca Raton, FL.

Houlard M, Berlivet S, Probst AV, Quivy JP, Hery P, Almouzni G, Gerard M. 2006. CAF-1 is essential for heterochromatin organization in pluripotent embryonic cells. PLoS Genet 2: e181.

Huberman JA, Riggs AD. 1966. Autoradiography of chromosomal DNA fibers from Chinese hamster cells. Proc Natl Acad Sci 96: 11434-11439.

Huberman JA, Riggs AD. 1968. On the mechanism of DNA replication in mammalian chromosomes. J Mol Biol 32: 327-341.

Huen MS, Sy SM, van Deursen JM, Chen J. 2008. Direct interaction between SET8 and proliferating cell nuclear antigen couples H4K20 methylation with DNA replication. J Biol Chem 283: 1107311077.
Ishimi Y, Komamura Y, You Z, Kimura H. 1998. Biochemical function of mouse minichromosome maintenance 2 protein. J Biol Chem 273: $8369-8375$

Jansen LE, Black BE, Foltz DR, Cleveland DW. 2007. Propagation of centromeric chromatin requires exit from mitosis. J Cell Biol 176: $795-805$.

Jasencakova Z, Scharf AND, Ask K, Corpet A, Imhof A, Almouzni G, Groth A. 2010. Replication stress interferes with histone recycling and predisposition marking of new histones. Mol Cell 37: 736-743.

Jones PL, Veenstra GJC, Wade PA, Vermaak D, Kass SU, Landsberg N, Strouboulis J, Wolffe AP. 1998. Methylated DNA and MeCP2 recruit histone deacetylase to repress transcription. Nat Genet 19: 187-191.

Jorgensen S, Elvers I, Trelle MB, Menzel T, Eskildsen M, Jensen ON, Helleday T, Helin K, Sorensen CS. 2007. The histone methyltransferase SET8 is required for S-phase progression. J Cell Biol 179: 1337-1345.

Kaufman PD, Kobayashi R, Kessler N, Stillman B. 1995. The p150 and p60 subunits of chromatin assembly factor I: A molecular link between newly synthesized histones and DNA replication. Cell 81: 1105-1114.

Kimura H, Cook PR. 2001. Kinetics of core histones in living human cells: Little exchange of $\mathrm{H} 3$ and $\mathrm{H} 4$ and some rapid exchange of $\mathrm{H} 2 \mathrm{~B} . J$ Cell Biol 153: 1341-1353.

Kitsberg D, Selig S, Brandeis M, Simon I, Keshet I, Driscoll DJ, Nicholls RD, Cedar H. 1993a. Allele-specific replication timing of imprinted gene regions. Nature 364: 459-463.

Kitsberg D, Selig S, Keshet I, Cedar H. 1993b. Replication structure of the human $\beta$-globin gene domain. Nature 366: 588-590.

Klapholz B, Dietrich BH, Schaffner C, Heredia F, Quivy JP, Almouzni G, Dostatni N. 2009. CAF-1 is required for efficient replication of euchromatic DNA in Drosophila larval endocycling cells. Chromosoma 118: 235-248.

Kloc A, Martienssen R. 2008. RNAi, heterochromatin and the cell cycle. Trends Genet 24: 511-517.

Krogan NJ, Cagney G, Zhong G, Guo X, Ignatchenko A, Datta N, Tikuisis AP, Punna T, Peregrin-Alvarez JM, Shales M, et al. 2006. Global landscape of protein complexes in the yeast Saccharomyces cerevisiae. $\mathrm{Na}$ ture 440: 637-643.

Lachner M, O'Carroll D, Rea S, Mechtler K, Jenuwein T. 2001. Methylation of histone $\mathrm{H} 3$ lysine 9 creates a binding site for HP1 proteins. Nature 410: 116-120.

Lande-Diner L, Zhang J, Ben-Porath I, Amariglio N, Keshet I, Hecht M, Azuara V, Fisher AG, Rechavi G, Cedar H. 2007. Role of DNA methylation in stable gene repression. J Biol Chem 282: 12194-12200.

Lande-Diner L, Zhang J, Cedar H. 2009. Shifts in replication timing actively affect histone acetylation during nucleosome reassembly. Mol Cell 34: 767-774.

Laskey RA, Mills AD, Morris NR. 1977. Assembly of SV40 chromatin in a cell-free system from Xenopus eggs. Cell 10: 237-243.

Laurent L, Wong E, Li G, Huynh T, Tsirigos A, Ong CT, Low HM, Kin Sung KW, Rigoutsos I, Loring J, et al. 2010. Dynamic changes in the human methylome during differentiation. Genome Res 20: 320-331.

Le S, Davis C, Konopka JB, Sternglanz R. 1997. Two new S-phase-specific genes from Saccharomyces cerevisiae. Yeast 13: 1029-1042.

* Li E, Zhang Y. 2014. DNA methylation in mammals. Cold Spring Harb Perspect Biol 6: a019133.

Li E, Bestor TH, Jaenisch R. 1992. Targeted mutation of the DNA methyltransferase gene results in embryonic lethality. Cell 69: 915-926.

Li E, Beard C, Jaenisch R. 1993. Role for DNA methylation in genomic imprinting. Nature 366: 362-365.

* Lomvardas S, Maniatis T. 2014. Histone and DNA modifications as regulators of neuronal development and function. Cold Spring Harb Perspect Biol doi: 10.1101/cshperspect. a019489.

Loppin B, Bonnefoy E, Anselme C, Laurencon A, Karr TL, Couble P. 2005. The histone H3.3 chaperone HIRA is essential for chromatin assembly in the male pronucleus. Nature 437: 1386-1390.

Loyola A, Almouzni G. 2007. Marking histone H3 variants: How, when and why? Trends Biochem Sci 32: 425-433. 
Loyola A, Bonaldi T, Roche D, Imhof A, Almouzni G. 2006. PTMs on H3 variants before chromatin assembly potentiate their final epigenetic state. Mol Cell 24: 309-316.

Loyola A, Tagami H, Bonaldi T, Roche D, Quivy JP, Imhof A, Nakatani Y, Dent SY, Almouzni G. 2009. The HP1 $\alpha$-CAF1-SetDB1-containing complex provides $\mathrm{H} 3 \mathrm{~K} 9 \mathrm{me} 1$ for Suv39-mediated K9me3 in pericentric heterochromatin. EMBO Rep 10: 769-775.

Lucchini R, Sogo JM. 1995. Replication of transcriptionally active chromatin. Nature 374: 276-280.

MacAlpine DM, Almouzni G. 2013. Chromatin and DNA replication. Cold Spring Harb Perspect Biol 5: a010207.

Malay AD, Umehara T, Matsubara-Malay K, Padmanabhan B, Yokoyama S. 2008. Crystal structures of fission yeast histone chaperone Asf1 complexed with the Hip1 B-domain or the Cac2 C terminus. J Biol Chem 283: 14022-14031.

Margueron R, Justin N, Ohno K, Sharpe ML, Son J, Drury WJ, Voigt P, Martin SR, Taylor WR, De Marco V, et al. 2009. Role of the polycomb protein EED in the propagation of repressive histone marks. Nature 461: $762-767$.

Marzluff WF, Wagner EJ, Duronio RJ. 2008. Metabolism and regulation of canonical histone mRNAs: Life without a poly(A) tail. Nat Rev Genet 9: 843-854.

Maze I, Noh KM, Soshnev AA, Allis CD. 2014. Every amino acid matters: Essential contributions of histone variants to mammalian development and disease. Nat Rev Genet 15: 259-271.

McKittrick E, Gafken PR, Ahmad K, Henikoff S. 2004. Histone H3.3 is enriched in covalent modifications associated with active chromatin. Proc Natl Acad Sci 101: 1525-1530.

Meeks-Wagner D, Hartwell LH. 1986. Normal stoichiometry of histone dimer sets is necessary for high fidelity of mitotic chromosome transmission. Cell 44: 43-52.

Mello JA, Sillje HH, Roche DM, Kirschner DB, Nigg EA, Almouzni G. 2002. Human Asf1 and CAF-1 interact and synergize in a repair-coupled nucleosome assembly pathway. EMBO Rep 3: 329-334.

Milutinovic S, Zhuang Q, Szyf M. 2002. Proliferating cell nuclear antigen associates with histone deacetylase activity, integrating DNA replication and chromatin modification. J Biol Chem 277: 20974-20978.

Moggs JG, Grandi P, Quivy JP, Jonsson ZO, Hubscher U, Becker PB, Almouzni G. 2000. A CAF-1-PCNA-mediated chromatin assembly pathway triggered by sensing DNA damage. Mol Cell Biol 20: 12061218.

Monk M, Boubelik M, Lehnert S. 1987. Temporal and regional changes in DNA methylation in the embryonic, extraembryonic and germ cell lineages during mouse embryo development. Development 99: 371382 .

Mostoslavsky R, Singh N, Tenzen T, Goldmit M, Gabay C, Elizur S, Qi P, Reubinoff BE, Chess A, Cedar H, et al. 2001. Asynchronous replication and allelic exclusion in the immune system. Nature 414: 221-225.

Muramoto T, Muller I, Thomas G, Melvin A, Chubb JR. 2010. Methylation of $\mathrm{H} 3 \mathrm{~K} 4$ is required for inheritance of active transcriptional states. Curr Biol 20: 397-406.

Murzina N, Verreault A, Laue E, Stillman B. 1999. Heterochromatin dynamics in mouse cells: Interaction between chromatin assembly factor 1 and HP1 proteins. Mol Cell 4: 529-540.

Nakatani Y, Ray-Gallet D, Quivy JP, Tagami H, Almouzni G. 2004. Two distinct nucleosome assembly pathways: Dependent or independent of DNA synthesis promoted by histone H3.1 and H3.3 complexes. Cold Spring Harb Symp Quant Biol 69: 273-280.

Nan X, Ng HH, Johnson CA, Laherty CD, Turner BM, Eisenman RN, Bird A. 1998. Transcriptional repression by the methyl-CpG-binding protein MeCP2 involves a histone deacetylase complex. Nature 393: 386-389.

Natsume R, Eitoku M, Akai Y, Sano N, Horikoshi M, Senda T. 2007. Structure and function of the histone chaperone CIA/ASF1 complexed with histones H3 and H4. Nature 446: 338-341.
Ng RK, Gurdon JB. 2008. Epigenetic memory of an active gene state depends on histone H3.3 incorporation into chromatin in the absence of transcription. Nat Cell Biol 10: 102-109.

Oda H, Okamoto I, Murphy N, Chu J, Price SM, Shen MM, TorresPadilla ME, Heard E, Reinberg D. 2009. Monomethylation of histone H4-lysine 20 is involved in chromosome structure and stability and is essential for mouse development. Mol Cell Biol 29: 2278-2295.

Ofir R, Wong AC, McDermid HE, Skorecki KL, Selig S. 1999. Position effect of human telomeric repeats on replication timing. Proc Natl Acad Sci 96: 11434-11439.

Osakabe A, Tachiwana H, Matsunaga T, Shiga T, Nozawa RS, Obuse C, Kurumizaka H. 2010. Nucleosome formation activity of human somatic nuclear autoantigenic sperm protein (sNASP). J Biol Chem 285: 11913-11921.

Papait R, Pistore C, Negri D, Pecoraro D, Cantarini L, Bonapace IM. 2007. Np95 is implicated in pericentromeric heterochromatin replication and in major satellite silencing. Mol Biol Cell 18: 1098-1106.

Parthun MR. 2007. Hat 1: The emerging cellular roles of a type B histone acetyltransferase. Oncogene 26: 5319-5328.

Perk J, Makedonski K, Lande L, Cedar H, Razin A, Shemer R. 2002. The imprinting mechanism of the Prader-Willi/Angelman regional control center. EMBO J 21: 5807-5814.

Perry P, Sauer S, Billon N, Richardson WD, Spivakov M, Warnes G, Livesey FJ, Merkenschlager M, Fisher AG, Azuara V. 2004. A dynamic switch in the replication timing of key regulator genes in embryonic stem cells upon neural induction. Cell Cycle 3: 1645-1650.

* Pikaard CS, Mittelsten Scheid O. 2014. Epigenetic regulation in plants. Cold Spring Harb Perspect Biol doi: 10.1101/cshperspect.a019315.

Pollack Y, Stein R, Razin A, Cedar H. 1980. Methylation of foreign DNA sequences in eukaryotic cells. Proc Natl Acad Sci 77: 6463-6467.

Polo SE, Roche D, Almouzni G. 2006. New histone incorporation marks sites of UV repair in human cells. Cell 127: 481-493.

Pradhan S, Bacolla A, Wells RD, Roberts RJ. 1999. Recombinant human DNA (cytosine-5) methyltransferase. I. Expression, purification, and comparison of de novo and maintenance methylation. J Biol Chem 274: 33002-33010.

Probst AV, Dunleavy E, Almouzni G. 2009. Epigenetic inheritance during the cell cycle. Nat Rev Mol Cell Biol 10: 192-206.

Quivy JP, Grandi P, Almouzni G. 2001. Dimerization of the largest subunit of chromatin assembly factor 1: Importance in vitro and during Xenopus early development. EMBO J 20: 2015-2027.

Quivy JP, Roche D, Kirschner D, Tagami H, Nakatani Y, Almouzni G. 2004. A CAF-1 dependent pool of HP1 during heterochromatin duplication. EMBO J 23: 3516-3526.

Quivy JP, Gerard A, Cook AJ, Roche D, Almouzni G. 2008. The HP1p150/CAF-1 interaction is required for pericentric heterochromatin replication and S-phase progression in mouse cells. Nat Struct Mol Biol 15: $972-979$.

Raghuraman MK, Brewer BJ, Fangman WL. 1997. Cell cycle-dependent establishment of a late replication program. Science 276: 806-809.

Ramsperger U, Stahl H. 1995. Unwinding of chromatin by the SV40 large T antigen DNA helicase. EMBO J 14: 3215-3225.

Ray-Gallet D, Quivy JP, Sillje HW, Nigg EA, Almouzni G. 2007. The histone chaperone Asf1 is dispensable for direct de novo histone deposition in Xenopus egg extracts. Chromosoma 19: 19.

Reese BE, Bachman KE, Baylin SB, Rountree MR. 2003. The methyl-CpG binding protein MBD1 interacts with the p150 subunit of chromatin assembly factor 1. Mol Cell Biol 23: 3226-3236.

Reik W, Walter J. 2001. Genomic imprinting: Parental influence on the genome. Nat Rev Genet 2: 21-32.

Robertson KD, Ait-Si-Ali S, Yokochi T, Wade PA, Jones PL, Wolffe AP. 2000. DNMT1 forms a complex with Rb, E2F1 and HDAC1 and represses transcription from E2F-responsive promoters. Nat Genet 25: $338-342$.

Rountree MR, Bachman KE, Baylin SB. 2000. DNMT1 binds HDAC2 and a new corepressor, DMAP1, to form a complex at replication foci. Nat Genet 25: 269-277. 
Sanematsu F, Takami Y, Barman HK, Fukagawa T, Ono T, Shibahara K, Nakayama T. 2006. Asf1 is required for viability and chromatin assembly during DNA replication in vertebrate cells. J Biol Chem 281: 13817- 13827.

Sarraf SA, Stancheva I. 2004. Methyl-CpG binding protein MBD1 couples histone $\mathrm{H} 3$ methylation at lysine 9 by SETDB1 to DNA replication and chromatin assembly. Mol Cell 15: 595-605.

Scharf AN, Barth TK, Imhof A. 2009a. Establishment of histone modifications after chromatin assembly. Nucleic Acids Res 37: 5032-5040.

Scharf AN, Meier K, Seitz V, Kremmer E, Brehm A, Imhof A. 2009b. Monomethylation of lysine 20 on histone $\mathrm{H} 4$ facilitates chromatin maturation. Mol Cell Biol 29: 57-67.

Schlesinger S, Selig S, Bergman Y, Cedar H. 2009. Allelic inactivation of rDNA loci. Genes Dev 23: 2437-2447.

Schuh M, Lehner CF, Heidmann S. 2007. Incorporation of Drosophila CID/CENP-A and CENP-C into centromeres during early embryonic anaphase. Curr Biol 17: 237-243.

Shelby RD, Monier K, Sullivan KF. 2000. Chromatin assembly at kinetochores is uncoupled from DNA replication. J Cell Biol 151: 11131118.

Shibahara K, Stillman B. 1999. Replication-dependent marking of DNA by PCNA facilitates CAF-1-coupled inheritance of chromatin. Cell 96: $575-585$.

Shibahara K, Verreault A, Stillman B. 2000. The N-terminal domains of histones $\mathrm{H} 3$ and $\mathrm{H} 4$ are not necessary for chromatin assembly factor1- mediated nucleosome assembly onto replicated DNA in vitro. Proc Natl Acad Sci 97: 7766-7771.

Shufaro Y, Lacham-Kaplan O, Tzuberi BZ, McLaughlin J, Trounson A, Cedar H, Reubinoff BE. 2010. Reprogramming of DNA replication timing. Stem Cells 28: 443-449.

Siegfried Z, Eden S, Mendelsohn M, Feng X, Tzubari B, Cedar H. 1999. DNA methylation represses transcription in vivo. Nat Genet 22: $203-$ 206.

Simon I, Tenzen T, Reubinoff BE, Hillman D, McCarrey JR, Cedar H. 1999. Asynchronous replication of imprinted genes is established in the gametes and maintained during development. Nature 401: 929932.

Simon I, Tenzen T, Mostoslavsky R, Fibach E, Lande L, Milot E, Gribnau J, Grosveld F, Fraser P, Cedar H. 2001. Developmental regulation of DNA replication timing at the human $\beta$ globin locus. EMBO J 20: 61506157.

Singh N, Ebrahimi FA, Gimelbrant AA, Ensminger AW, Tackett MR, Qi P, Gribnau J, Chess A. 2003. Coordination of the random asynchronous replication of autosomal loci. Nat Genet 33: 339-341.

Smith S, Stillman B. 1989. Purification and characterization of CAF-I, a human cell factor required for chromatin assembly during DNA replication in vitro. Cell 58: 15-25.

Sobel RE, Cook RG, Perry CA, Annunziato AT, Allis CD. 1995. Conservation of deposition-related acetylation sites in newly synthesized histones H3 and H4. Proc Natl Acad Sci 92: 1237-1241.

Sogo JM, Stahl H, Koller T, Knippers R. 1986. Structure of replicating simian virus 40 minichromosomes. The replication fork, core histone segregation and terminal structures. J Mol Biol 189: 189-204.

Song Y, He F, Xie G, Guo X, Xu Y, Chen Y, Liang X, Stagljar I, Egli D, Ma J, et al. 2007. CAF-1 is essential for Drosophila development and involved in the maintenance of epigenetic memory. Dev Biol 311: 213-222.

Stillman B. 1986. Chromatin assembly during SV40 DNA replication in vitro. Cell 45: 555-565.

Straussman R, Nejman D, Roberts D, Steinfeld I, Blum B, Benvenisty N, Simon I, Yakhini Z, Cedar H. 2009. Developmental programming of $\mathrm{CpG}$ island methylation profiles in the human genome. Nat Struct Mol Biol 16: $564-571$.

Taddei A, Roche D, Sibarita JB, Turner BM, Almouzni G. 1999. Duplication and maintenance of heterochromatin domains. J Cell Biol 147: $1153-1166$.
Taddei A, Maison C, Roche D, Almouzni G. 2001. Reversible disruption of pericentric heterochromatin and centromere function by inhibiting deacetylases. Nat Cell Biol 3: 114-120.

Tagami H, Ray-Gallet D, Almouzni G, Nakatani Y. 2004. Histone H3.1 and H3.3 complexes mediate nucleosome assembly pathways dependent or independent of DNA synthesis. Cell 116: 51-61.

Tang Y, Poustovoitov MV, Zhao K, Garfinkel M, Canutescu A, Dunbrack R, Adams PD, Marmorstein R. 2006. Structure of a human ASFlaHIRA complex and insights into specificity of histone chaperone complex assembly. Nat Struct Mol Biol 13: 921-929.

Tardat M, Murr R, Herceg Z, Sardet C, Julien E. 2007. PR-Set7-dependent lysine methylation ensures genome replication and stability through S phase. J Cell Biol 179: 1413-1426.

Tyler JK, Adams CR, Chen SR, Kobayashi R, Kamakaka RT, Kadonaga JT. 1999. The RCAF complex mediates chromatin assembly during DNA replication and repair. Nature 402: 555-560.

Tyler JK, Collins KA, Prasad-Sinha J, Amiott E, Bulger M, Harte PJ, Kobayashi R, Kadonaga JT. 2001. Interaction between the Drosophila CAF-1 and ASF1 chromatin assembly factors. Mol Cell Biol 21: 65746584.

Unoki M, Nishidate T, Nakamura Y. 2004. ICBP90, an E2F-1 target, recruits HDAC1 and binds to methyl-CpG through its SRA domain. Oncogene 23: 7601-7610.

Vaute O, Nicolas E, Vandel L, Trouche D. 2002. Functional and physical interaction between the histone methyl transferase Suv39H1 and histone deacetylases. Nucleic Acids Res 30: 475-481.

Verreault A, Kaufman PD, Kobayashi R, Stillman B. 1996. Nucleosome assembly by a complex of CAF-1 and acetylated histones $\mathrm{H} 3 / \mathrm{H} 4$. Cell 87: 95-104.

Vestner B, Waldmann T, Gruss C. 2000. Histone octamer dissociation is not required for in vitro replication of simian virus 40 minichromosomes. J Biol Chem 275: 8190-8195.

Vogelauer M, Rubbi L, Lucas I, Brewere BJ, Grunstein M. 2002. Histone acetylation regulates the time of replication origin firing. Mol Cell 10: $1223-1233$.

Warburton PE, Cooke CA, Bourassa S, Vafa O, Sullivan BA, Stetten G, Gimelli G, Warburton D, Tyler-Smith C, Sullivan KF, et al. 1997. Immunolocalization of CENP-A suggests a distinct nucleosome structure at the inner kinetochore plate of active centromeres. Curr Biol 7: 901-904.

Weintraub H. 1974. The assembly of newly replicated DNA into chromatin. Cold Spring Harb Symp Quant Biol 38: 247-256.

Wigler M, Levy D, Perucho M. 1981. The somatic replication of DNA methylation. Cell 24: 33-40.

Wolffe AP, Pruss D. 1996. Deviant nucleosomes: The functional specialization of chromatin. Trends Genet 12: 58-62.

Wong LH, McGhie JD, Sim M, Anderson MA, Ahn S, Hannan RD, George AJ, Morgan KA, Mann JR, Choo KH. 2010. ATRX interacts with H3.3 in maintaining telomere structural integrity in pluripotent embryonic stem cells. Genome Res 20: $351-360$.

Wu RS, Tsai S, Bonner WM. 1982. Patterns of histone variant synthesis can distinguish G0 from G1 cells. Cell 31: 367-374.

Xie W, Song C, Young NL, Sperling AS, Xu F, Sridharan R, Conway AE, Garcia BA, Plath K, Clark AT, et al. 2009. Histone h3 lysine 56 acetylation is linked to the core transcriptional network in human embryonic stem cells. Mol Cell 33: 417-427.

Xu M, Long C, Chen X, Huang C, Chen S, Zhu B. 2010. Partitioning of histone H3-H4 tetramers during DNA replication-dependent chromatin assembly. Science 328: 94-98.

Zhang J, Feng X, Hashimshony T, Keshet I, Cedar H. 2002. Establishment of transcriptional competence in early and late S-phase. Nature 420: 198-202.

Zlatanova J, Seebart C, Tomschik M. 2007. Nap1: Taking a closer look at a juggler protein of extraordinary skills. FASEB J 21: 1294-1310. 


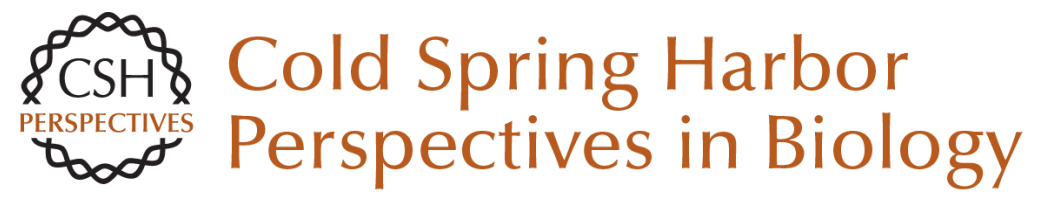

\section{Maintenance of Epigenetic Information}

Geneviève Almouzni and Howard Cedar

Cold Spring Harb Perspect Biol 2016; doi: 10.1101/cshperspect.a019372

Subject Collection Epigenetics

Metabolic Signaling to Chromatin Shelley L. Berger and Paolo Sassone-Corsi

Histone and DNA Modifications as Regulators of Neuronal Development and Function Stavros Lomvardas and Tom Maniatis

Histone Modifications and Cancer James E. Audia and Robert M. Campbell

Epigenetics and Human Disease Huda Y. Zoghbi and Arthur L. Beaudet

Induced Pluripotency and Epigenetic Reprogramming Konrad Hochedlinger and Rudolf Jaenisch

Long-Range Chromatin Interactions Job Dekker and Tom Misteli

RNAi and Heterochromatin Assembly Robert Martienssen and Danesh Moazed

Dosage Compensation in Drosophila John C. Lucchesi and Mitzi I. Kuroda
Epigenetic Determinants of Cancer Stephen B. Baylin and Peter A. Jones

Maintenance of Epigenetic Information Geneviève Almouzni and Howard Cedar

A Structural Perspective on Readout of Epigenetic Histone and DNA Methylation Marks Dinshaw J. Patel

The Necessity of Chromatin: A View in

Perspective Vincenzo Pirrotta

Germline and Pluripotent Stem Cells Wolf Reik and M. Azim Surani

Comprehensive Catalog of Currently Documented Histone Modifications Yingming Zhao and Benjamin A. Garcia

Epigenetic Regulation of Chromatin States in Schizosaccharomyces pombe Robin C. Allshire and Karl Ekwall

Histone Variants and Epigenetics Steven Henikoff and M. Mitchell Smith

For additional articles in this collection, see http://cshperspectives.cshlp.org/cgi/collection/

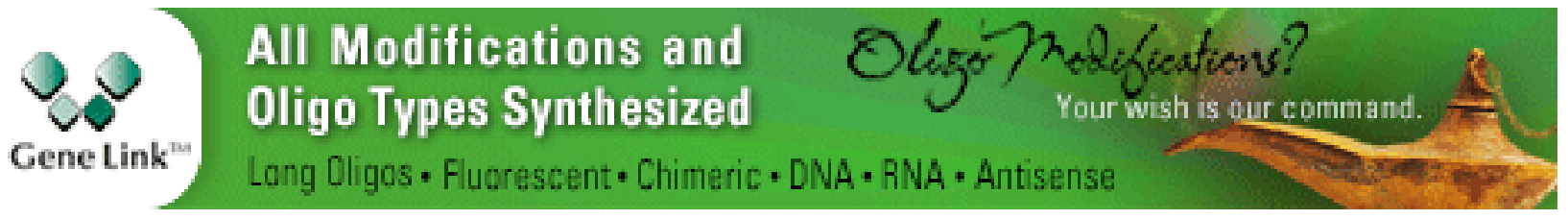

Copyright @ 2016 Cold Spring Harbor Laboratory Press; all rights reserved 
For additional articles in this collection, see http://cshperspectives.cshlp.org/cgi/collection/

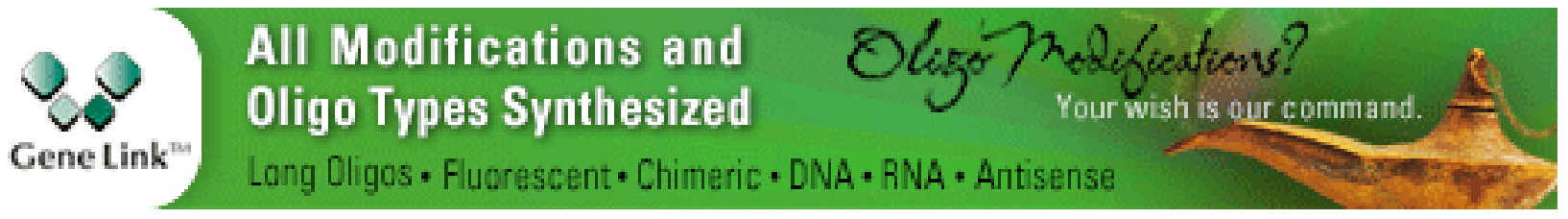

Copyright @ 2016 Cold Spring Harbor Laboratory Press; all rights reserved 